\title{
Journal of

\section{Novel lithium Schiff-base cluster complexes as electron injectors: synthesis, crystal structure, thin film characterisation and their performance in OLEDs $\dagger$}

\author{
Poopathy Kathirgamanathan, ${ }^{* a}$ Sivagnanasundram Surendrakumar, ${ }^{a}$ Juan Antipan-Lara, ${ }^{a}$ \\ Seenivasagam Ravichandran, ${ }^{a}$ Y. F. Chan, ${ }^{a}$ Vincent Arkley, ${ }^{a}$ Subramanium Ganeshamurugan, ${ }^{a}$ \\ Muttulingham Kumaraverl, ${ }^{a}$ Gnanamoly Paramswara, ${ }^{a}$ Arumugam Partheepan, ${ }^{a}$ Vanga R. Reddy, ${ }^{a}$ \\ Daniel Bailey ${ }^{b}$ and Alexander J. Blake ${ }^{* b}$
}

Received 10th October 2011, Accepted 9th January 2012

DOI: $10.1039 / c 2 j m 15114 f$

\begin{abstract}
A set of novel lithium Schiff base cluster compounds has been synthesised and characterised for the first time and tested as electron injectors in OLED devices. Their electrical, electronic, thermal and optical properties have been investigated and compared with the industry standards LiF and lithium quinolinolate (LiQ). Amongst the compounds tested, lithium 2-((o-tolylimino)methyl) phenolate was found to enhance the efficiency of OLEDs by $69 \%$ compared to $\mathrm{LiF}$ and $15 \%$ compared to LiQ. The same electron injector was found to extend the lifetimes of OLEDs by six-fold compared to LiF and 4.3fold compared to LiQ respectively. The crystal structure of the parent compound, lithium 2-

((phenylamino)methyl)phenolate reveals that the compound is tetrameric in contrast to hexameric $\mathrm{LiQ}$. Substituting the methyl group with fluorine causes a remarkable depression of the HOMO and LUMO levels by up to $1.2 \mathrm{eV}$. Analysis of current density $v$. voltage characteristics of single-layer devices for $\mathrm{Li}-\mathrm{Al} /$ electron injector/Li-Al and $\mathrm{Al} /$ electron injector/Al reveals that both sets of devices are operating as electron-only devices indicating that the formation of free lithium is the cause of enhanced electron injection, but either the energetic aluminium atoms (as proposed previously by other workers) or energetic lithium complexes on an aluminium surface (as we have demonstrated in this paper) are all that is required for efficient electron injection.
\end{abstract}

\section{Introduction}

Organic light emitting diodes have been the subject of intense investigation due to their increasing applications in displays (e.g., Samsung mobile phones, Sony's AM-OLED TV) and lighting (Philips, Osram and Pioneer). ${ }^{1-4}$ The recent announcement by Samsung of its intention to invest 2.2 billion US Dollars into active matrix OLED television (AM-OLED) to bring it into the mainstream TV market has given considerable impetus to the scientists developing materials for the OLED devices.

OLEDs are multilayer devices, typically composed of (i) a hole injector (e.g., copper phthalocyanine $(\mathrm{CuPc}), 4,4^{\prime}, 4^{\prime \prime}$-tris $[N-(2-$ naphthyl)- $N$-phenyl-amino)-triphenylamine (2-TNATA), tripyrazinocyclohexane(s); ${ }^{1-3}$ (ii) a hole transporter (e.g., $N, N^{\prime}$-bis(1-naphthalenyl)- $N, N^{\prime}$-bis-phenyl-(1,1'-biphenyl)-4,4'-diamine, $\alpha-\mathrm{NPB}$ ); (iii) an emissive layer (host + dopant); (iv) an electron

${ }^{a}$ Organic Electronics, Wolfson Centre, Brunel University, Uxbridge, UB8 3PH,UK.E-mail: p.kathir@brunel.ac.uk

${ }^{b}$ School of Chemistry, The University of Nottingham, University Park, Nottingham, NG7 2RD, UK

$\dagger$ Electronic supplementary information (ESI) available. CCDC reference number 847975 . For ESI and crystallographic data in CIF or other electronic format see DOI: 10.1039/c2jm15114f transporter (e.g., tris(8-hydroxyquinoline)-aluminium $\left(\mathrm{Alq}_{3}\right)$ ); (v) an electron injector (e.g., LiF, CsF, lithium quinolinolates) and (vi) a cathode (e.g., Al $)^{4-6}$ to provide charge balance so that efficient devices can be produced. Hole transporters and electron transporters can also be doped with an acceptor or donor, respectively, to increase the conductivities of the respective layers. ${ }^{5-7}$

There are continuing demands for reductions in the operating voltage and power consumption of OLEDs, while achieving increased lifetimes is also a priority. Charge transport (hole and electron) materials, whether pure or doped, are an integral part of any OLED. It has been reported ${ }^{9}$ that nearly $60 \%$ of the total electrical power is lost through the charge transport layers, of which nearly $36 \%$ is through the electron transporting layer, $5.7 \%$ through the electron injecting layer and the remainder through the hole injection layer, hole transporting layer and the hole blocking layer. The lifetime is also critically dependent on the nature of the charge transporters employed. Improvements in efficiencies of up to $70 \%$ have been reported in otherwise identical devices by Kathirgamanathan et al. ${ }^{2}$ and Kido et al. ${ }^{8}$ when $\mathrm{Alq}_{3}$ is replaced by novel electron transporters.

In order to produce an efficient OLED, the anode should have as high a work function (W.F.) as possible so that the barrier for 
the hole injection is minimised, while the cathode should have as low a work function as possible so that the barrier for electron injection is reduced. ${ }^{10-12}$ Despite its high work function (W.F.) of $4.2 \mathrm{eV}$, aluminium has been widely used as a cathode because of its reasonably high air stability and ease of deposition.

In 1976, Partridge employed low work function Cs metal $\left(\mathrm{W} . \mathrm{F} .=2.0 \mathrm{eV}\right.$ ) as an efficient cathode ${ }^{13}$ on polymer OLEDs and later Tang and Van Slyke ${ }^{14,15}$ employed a Mg/Ag alloy (W.F. = $3.7 \mathrm{eV}$ ). This was followed by the use of low work function $\mathrm{Ca}$ and Ba electrodes by Burroughes et al. in 1990 (ref. 16). All these low work function metals are extremely sensitive to moisture and oxygen and therefore not very practical in an industrial manufacturing environment. In 1997, Kido et al. demonstrated the use of a stable Li/Al alloy (W.F. $=2.8 \mathrm{eV}$ ) as a cathode, significantly reducing the operating voltage. ${ }^{17}$ In the same year, Wakimoto et al. ${ }^{18}$ showed that various alkali metal compounds (e.g., $\mathrm{Li}_{2} \mathrm{O}, \mathrm{Cs}_{2} \mathrm{O}, \mathrm{NaCl}, \mathrm{KCl}$ and $\mathrm{RbCl}$ ) in conjunction with an Al cathode were as effective as the Li/Al alloy as far as the electron injection is concerned, effecting a three-fold improvement in efficiency and a $35 \%$ reduction in operating voltage. It was also noteworthy that the lifetimes of OLED devices with $\mathrm{Li} / \mathrm{Al}$ or $\mathrm{Li}_{2} \mathrm{O} / \mathrm{Al}$ cathodes were three times as long as those with $\mathrm{Mg} / \mathrm{Al}$ cathodes. ${ }^{18}$

The reduction in operating voltage from lithium compounds or alloys is due to the low work function of this metal (W.F. = $2.2 \mathrm{eV}$ ). The use of Li/Al alloys does not always result in reproducible devices under large scale manufacturing vacuum evaporation conditions: this is because they contain varying compositions of the individual metals as a result of these exhibiting different vapour pressures and densities. To alleviate this problem, Hung et al. employed a thin layer of LiF (0.1-1 nm) as an electron injector and found that the reduction in operating voltage was comparable to that obtained with Li/Al alloys. ${ }^{19}$

Hung et al. ${ }^{19}$ examined the $\mathrm{Alq}_{3} / \mathrm{LiF} / \mathrm{Al}$ interface of the device (ITO/ $\alpha$-NPB $\left.(75 \mathrm{~nm}) / \mathrm{Alq}_{3}(70 \mathrm{~nm}) / \mathrm{LiF}(0.3 \mathrm{~nm}) / \mathrm{Al}(100 \mathrm{~nm})\right)$ by high resolution electron energy loss spectroscopy (HREELS) and postulated that the mechanism for reduction in operating voltage compared to the $\mathrm{Alq}_{3} / \mathrm{Al}$ interface involves the formation of free $\mathrm{Li}$ metal at the organics/Al interface, thereby reducing the W.F. Interfacial studies by synchrotron radiation photoemission spectroscopy revealed that there is a reaction between $\mathrm{LiF}$ and the highly reactive aluminium atoms produced during vacuum thermal evaporation. ${ }^{19,20}$ On this basis, Hung et al. proposed the following interfacial reaction which is claimed to be thermodynamically feasible: ${ }^{19,20}$

$$
3 \mathrm{LiF}+\mathrm{Al}+3 \mathrm{Alq}_{3} \rightarrow \mathrm{AlF}_{3}+3 \mathrm{Li}^{+} \mathrm{Alq}_{3}
$$

However, Wong et al. $^{21}$ reported the use of LiF to reduce the W.F. of diamond surfaces via the dipole effect induced by $\mathrm{LiF}$ (which has a very high dipole moment of $6.33 \pm 0.63$ Debye). For example, the W.F. of the hydrogenated diamond decreased from $4.4 \mathrm{eV}$ (virgin) to $2.4 \mathrm{eV}$ on depositing $1.5 \mathrm{~nm}$ of $\mathrm{LiF}$ and the W.F. of oxygenated diamond dropped from $3.6 \mathrm{eV}$ to $2.4 \mathrm{eV}$. The question therefore arises of whether the reaction given in eqn (1) is critical for the reduction in the operating voltage in an OLED device.

Moreover, LiF has three major drawbacks: (a) it is an insulator and thus the thickness of the deposit has to be kept below
$1 \mathrm{~nm}$ so that the operating voltage does not increase; (b) it requires very high temperatures $\left(500-600{ }^{\circ} \mathrm{C}\right)$ to evaporate even under high vacuum, requiring expensive crucibles; (c) it is hygroscopic.

To alleviate the problems with LiF, complexes such as lithium quinolinolate (LiQ, EI-101) have been employed as electron injectors with considerable success even on an industrial scale because: (a) it evaporates at much lower temperatures (200-300 $\left.{ }^{\circ} \mathrm{C}\right)$; (b) it is air stable; and (c) it is not hygroscopic.

We first reported the synthesis of thermally stable, solventfree and sublimable high purity $\mathrm{LiQ}^{22}$ which was later structurally characterised as hexameric (Liq) 6 by X-ray diffraction. $^{23}$ The oligomeric nature (clusters) of lithium complexes explains their low evaporation temperatures and air stability. Indeed, most lithium complexes occur as cluster compounds: for example lithium(2-methyl-8-hydroxyquinolinolate) is a hexamer while lithium(2-phenyl-8-hydroxyquinolinolate) is a tetramer. ${ }^{24}$

(Liq) ${ }_{6}$ has been found to be a good electron injector as well as a good host material in some cases, but does not function as an effective electron transporter because of its poor electrical conductivity $\left(<1 \times 10^{-11} \mathrm{~S} \mathrm{~cm}^{-1}\right)$. However, it has been used as an admixture in conjunction with other electron transporters such as $\mathrm{Alq}_{3}, \mathrm{Zrq}_{4}$ and some anthracene derivatives ${ }^{25}$ to modulate the electron mobility and enhance the lifetime. However, no data on lifetime or voltage drift have been reported where LiQ was employed as an electron injector or in an admixture with any electron transporters.

Several other complexes of lithium, namely, 2,3-diphenyl-5hydroxyquinoxalinatolithium and lithium(hydroxyphenylbenzoxazole(s) have also been found to act as good electron injectors. ${ }^{10,26,27}$ It is noteworthy that while $\mathrm{Pu}$ et al. ${ }^{28}$ have reported the potential use of some lithium complexes [e.g., lithium 2-( $2^{\prime}, 2^{\prime \prime}$-bipyridine- $6^{\prime}$-yl $)$ phenolate (LiBPP), lithium2-(isoquinoline-1'-yl)phenolate (LiIQP)] as very efficient electron injectors-cum-electron transporters; their effects on the lifetime (an important parameter) of the devices have not been disclosed, thereby questioning their wide applicability. Related compounds have also been published by Sun et al., but again no lifetime data were provided. ${ }^{33}$

Although LiQ has been used since the 1960 's, ${ }^{29}$ a recent toxicological study employing the Ames Test ${ }^{30-32}$ showed that LiQ exhibits mutagenic activity $(70 \mu \mathrm{g}$ per plate, in the histidinedependent auxotropic mutant Salmonella typhimurium, Strain TA100). ${ }^{30-32}$

We have been interested in OLED materials in general and electron injectors in particular for the past 18 years, during which period we made a large number of lithium complexes in our quest for non-toxic (or less toxic) electron injectors with superior performance to LiQ. This paper describes the synthesis of lithium complexes (clusters) of some selected Schiff bases (reaction scheme shown below) from a large number of complexes made by us and their performance in OLEDs in comparison to the industrial standard $\mathrm{LiF}$ and $\mathrm{LiQ}$ for the first time. We also examine their mechanism of conduction and carrier injection, and their effect on the lifetime and the voltage drift during device operation. This paper also investigates the interactions of these novel compounds with the electrode (Al) and the electron transporter $\left(\mathrm{Zrq}_{4}\right)$. 


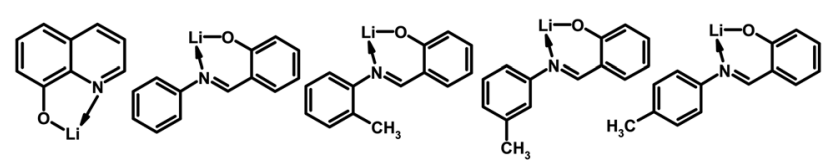

EI-101

EI-111

EI-111-2Me

EI-111-3Me

EI-111-4Me

\section{Experimental}

The lithium complexes were prepared by the following general route: (Schemes 1 and 2).

The lithium Schiff-base complexes reported herein have been made in 20 g quantities and triply sublimed to give $99.9 \%$ purity materials. Although the synthetic yield of the reaction is between 75 and $95 \%$ for analytically pure samples, the sublimation yields (Table 1) were substantially different. EI-111-2Me was found to give the highest sublimation yield.

\section{Device fabrications and measurements}

Electron-only devices were fabricated by evaporating the electron injectors (EI-101 (LiQ), EI-111 or EI-111-2Me) to produce a layer thickness of $40-50 \mathrm{~nm}$ onto $\mathrm{Li}-\mathrm{Al}(2: 98)$ alloy coated ITO/glass and sandwiching it with a bottom contact of another layer of Li-Al alloy (200 nm) (System A). Other single-layer devices with $\mathrm{Al}$ or ITO as the anode and $\mathrm{Al}, \mathrm{Li}-\mathrm{Al}$ or $\mathrm{Au}$ as the cathode have been constructed in order to investigate the dependence of work function on the mechanism of conduction: these are devices of the type ITO/EI/Al (mixed conduction, System C), ITO/EI/Au (hole-only, System D) and ITO/Al/EI/Al (System B) to test the effect of $\mathrm{Al}$ interaction on EI (to be discussed later).

Electroluminescent devices were fabricated by thermal evaporation using a multi-chamber OLED pilot plant machine (Solciet, manufactured by ULVAC, Japan). The devices were fabricated on a patterned (pixelated) ITO substrate (surface resistance of $40 \Omega$ per square Hitachi High Tech., Japan), cleaned with water, acetone, isopropyl alcohol and water (in that order), then dried at $150{ }^{\circ} \mathrm{C}$ for 20 minutes and then subjected to ozone cleaning (UV irradiation, $185 \mathrm{~nm}$ ) at $150{ }^{\circ} \mathrm{C}$ for 10 minutes. The substrate was then plasma-cleaned in the presence of oxygen for 25 seconds and moved into the vacuum chamber from which the hole injector $[(5,10,15,20$-tetra $(p$-tolyl $)-21 H, 23 H$-porphine $)$

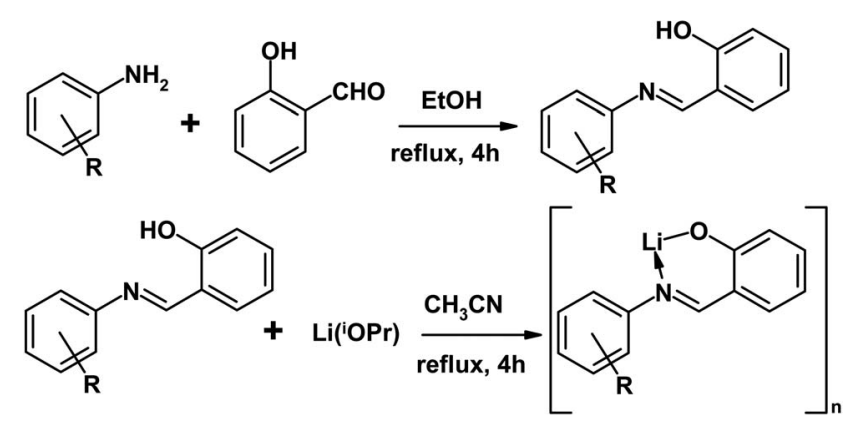

Scheme 1 Synthesis of lithium (phenyliminomethyl)phenolate derivatives EI-111 $(\mathrm{R}=\mathrm{H})$; EI-111-2Me $(\mathrm{R}=2 \mathrm{Me})$; EI-111-3Me $(\mathrm{R}=3 \mathrm{Me})$, EI-111-4Me $(\mathrm{R}=4 \mathrm{Me})$ EI-111-2F $(\mathrm{R}=2 \mathrm{~F})$; EI-111-3F $(\mathrm{R}=3 \mathrm{~F})$ and EI$111-4 \mathrm{~F}(\mathrm{R}=4 \mathrm{~F})$.

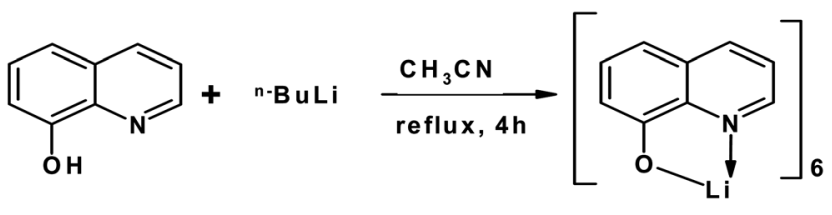

Scheme 2 Synthesis of lithium quinolinolate.

Table 1 Synthetic and sublimation yields for lithium Schiff-base complexes

\begin{tabular}{lll}
\hline Material & Synthetic yield (\%) & Sublimation yield (\%) \\
\hline EI-101 (LiQ) & 95 & 88 \\
EI-111 & 97 & 30 \\
EI-111-2Me & 93 & 75 \\
EI-111-3Me & 87 & 30 \\
EI-111-4Me & 75 & 30 \\
\hline
\end{tabular}

zinc(II) (ZnTPTP), $20 \mathrm{~nm}$, hole transporter [ $N, N^{\prime}$-bis(1-naphthalenyl)- $N, N^{\prime}$-bis-phenyl-(1,1'-biphenyl)-4,4'-diamine ( $\alpha$-NPB), $50 \mathrm{~nm}]$, host : dopant $\left[\mathrm{Alq}_{3}(50 \mathrm{~nm}):(0.1 \mathrm{~nm})\right.$ dopant $\left(N, N^{\prime}-\right.$ diphenylquinacridone) (DPQA), co-evaporation], electron transporter [either $\mathrm{Alq}_{3}$ or $\mathrm{Zrq}_{4}, 20 \mathrm{~nm}$ ] were sequentially deposited. The evaporation rates of ZnTPTP, $\alpha-\mathrm{NPB},\left(\mathrm{Alq}_{3}\right.$, DPQA), $\mathrm{Zrq}_{4}$ and $\mathrm{LiF}$ (electron injector) were $1 \AA^{\circ} \mathrm{s}^{-1}, 1.5 \mathrm{~A} \mathrm{~s}^{-1}$, $\left(1 \AA \mathrm{s}^{-1}, 0.1 \AA^{-1} \mathrm{~s}^{-1}\right), 0.05 \AA_{\mathrm{s}}^{-1}$ respectively. The evaporation rates of LiQ, EI-111 and EI-111-2Me were $0.5 \AA \mathrm{s}^{-1}$.

Directly from the vacuum chamber all the devices were encapsulated with a UV curable adhesive (Nagase) onto glass backplates in a glovebox filled with dry nitrogen so that the device is not exposed to air. The electrical and optical measurements were carried out by a computer-controlled Keithley 2400 Source Meter and a Minolta (CS-1000) spectrometer, respectively. HOMO-LUMO levels were determined by cyclic voltammetry (by computer-controlled potentiostat PAR 273 or CHI 600D) and from band gap measurements by absorption spectroscopy of thin films produced by vacuum thermal evaporation. Capacitance measurements were made on thin films as well as compacted discs using an Impedance Analyser (Hewlett Packard, 4284A). DC conductivity measurements of the materials were also performed on compacted discs using a two-probe method. ${ }^{35}$

\section{Crystal structure determination}

Single crystals of EI-111 suitable for single-crystal X-ray crystallographic studies were grown by slow vacuum sublimation at a temperature of $275^{\circ} \mathrm{C}$ and a pressure of $5 \times 10^{-6}$ Torr.

Crystal data for EI-111. $\mathrm{C}_{52} \mathrm{H}_{40} \mathrm{Li}_{4} \mathrm{~N}_{4} \mathrm{O}_{4}, M=812.64$, monoclinic, space group $P 2_{1} / c, a=10.4110(14), b=17.316(2), c=$ 24.493(3) ̊, $\beta=97.918(2)^{\circ}, U=4373.4(9) \AA^{3}, T=150(2) \mathrm{K}, Z=$ $4, D_{\mathrm{c}}=1.234 \mathrm{Mg} \mathrm{m}^{-3}, \mu(\mathrm{Mo}-\mathrm{K} \alpha)=0.077 \mathrm{~mm}^{-1}, 7787$ unique reflections $\left(R_{\text {int }}=0.048\right)$. Final $R_{1}[5302 F \geq 4 \sigma(F)]=0.0349$, $\mathrm{w} R 2($ all data $)=0.0861$.

\section{Results and discussion}

\section{Crystal structure}

In the crystal, EI-111 was found to be tetrameric and to adopt a slightly distorted $\mathrm{Li}_{4} \mathrm{O}_{4}$ cubane-type structure (Fig. 1) with $\mathrm{Li}-\mathrm{O}$ 


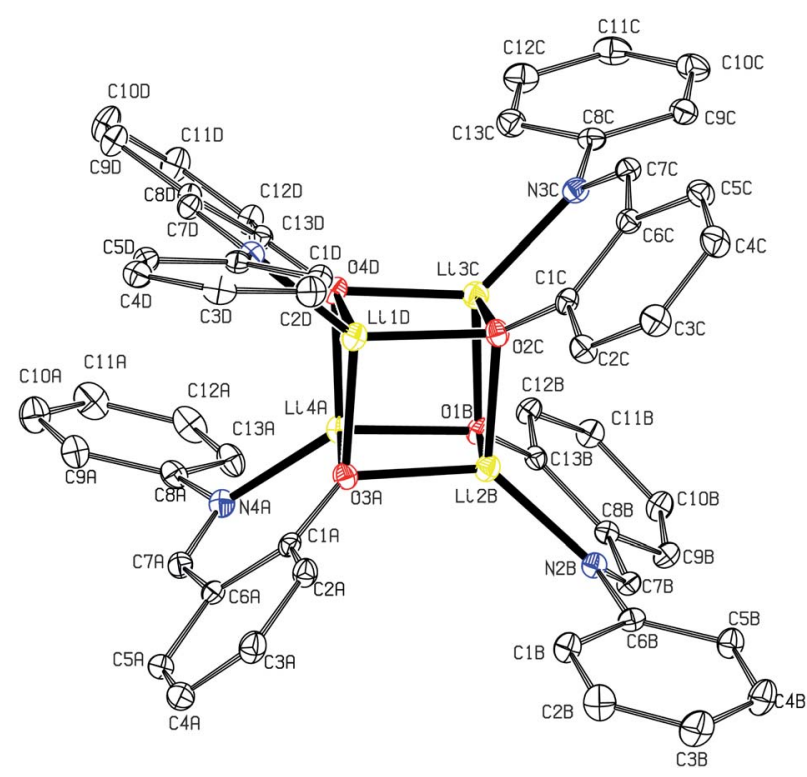

Fig. 1 Crystal structure of lithium 2-((phenylimino)methyl)phenolate (EI-111). Displacement ellipsoids are drawn at the $20 \%$ probability level and hydrogen atoms are omitted for clarity.

Table 2 Cluster size determination by mass spectroscopy (MS) and crystal structure analysis (XRD)

\begin{tabular}{lll}
\hline Compound & $\begin{array}{l}\text { No. of units in } \\
\text { the cluster by MS }\end{array}$ & $\begin{array}{l}\text { No. of units in the } \\
\text { cluster by XRD }\end{array}$ \\
\hline EI-101 (LiQ) & 6 & 6 \\
EI-111 & 4 & 4 \\
EI-111-2Me & 3 & Not available \\
EI-111-3Me & 3 & Not available \\
EI-111-4Me & 4 & Not available \\
\hline
\end{tabular}

distances of 1.902(3)-1.978(3) А, O-Li-O angles of 93.59(12)$97.09(12)^{\circ}$ and $\mathrm{Li}-\mathrm{O}-\mathrm{Li}$ angles of $83.22(11)-85.85(11)^{\circ} ; \mathrm{Li}-\mathrm{N}$ distances external to the $\mathrm{Li}_{4} \mathrm{O}_{4}$ cube span the range 1.966(3)1.993(3) A. Each of the four ligands therefore contributes one oxygen atom to the formation of the cubane via an $\mathrm{LiO}_{4}$ apex, with its nitrogen donor atom providing the cap of an adjacent $\mathrm{LiO}_{4} \mathrm{~N}$ apex. As a result, four of the eight $\mathrm{Li}-\mathrm{O}$ edges are bridged by a ligand. The individual ligands deviate significantly from planarity, with the dihedral angles between their phenyl rings ranging from $29.00(7)$ to $54.49(8)^{\circ}$. The structure does not exhibit specific directional intermolecular interactions, but layers of molecules are strongly interdigitated. (Fig. EI-111_PACK_A.PNG and EI-111_PACK_C.PNG, see ESI†े.)

\section{Cluster size}

Unlike the crystal structure of EI-111 which is tetrameric (see above), that of EI-101 (LiQ) is hexameric $\left[(\mathrm{Liq})_{6}\right] .{ }^{23} \mathrm{We}$ employed mass spectroscopy to establish the number of units present in each cluster. Although mass spectroscopy is a gas phase measurement, it gives useful information as to the cluster size. Further, it also confirms that layers of these materials produced on thermal evaporation are composed of clusters.

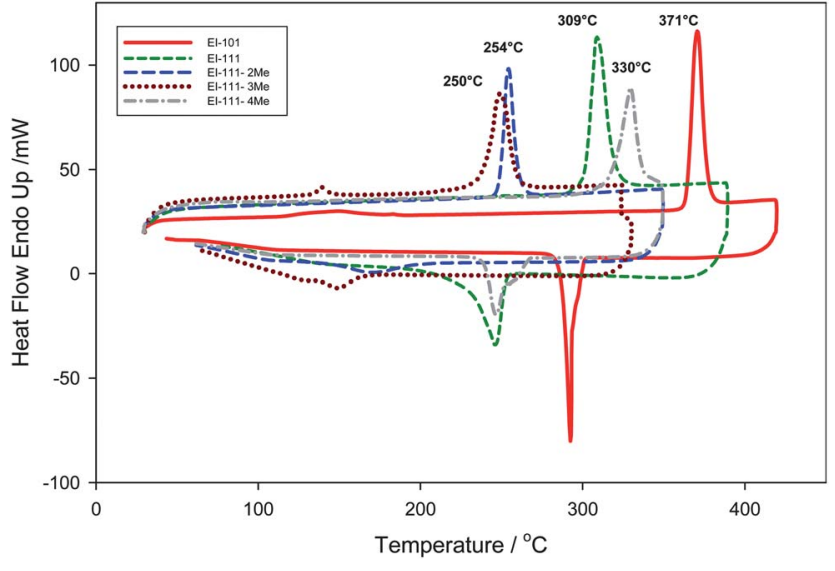

Fig. 2 Differential scanning calorimetry of EI-101 (LiQ), EI-111, EI111-2Me, EI-111-3Me, EI-111-4Me under nitrogen atmosphere. Scan rate: $30^{\circ} \mathrm{C}$ per minute.

Table 2 shows the results from both mass spectroscopy and crystal structure where available.

\section{Physical characteristics}

Thermal properties. Thermal properties were measured by differential scanning calorimetry (DSC) (Fig. 2) and thermogravimetric analysis (TGA) (Fig. 3). The results are summarised in Table 3.

As can be seen from Table 3, only LiQ shows a $T_{\mathrm{g}}$, although none of the lithium Schiff-base complexes reported here do. The lithium complexes with 2,3-dimethylaniline and 2,4-dimethyl aniline Schiff bases exhibit $T_{\mathrm{g}}$ values of $111^{\circ} \mathrm{C}$ and $95{ }^{\circ} \mathrm{C}$, respectively, whereas the 2,5-dimethyl derivative does not exhibit a $T_{\mathrm{g}}{ }^{43}$

TGA studies show that with one exception, namely EI-111-3Me, all the electron injectors are stable up to $260{ }^{\circ} \mathrm{C}$. EI-111-3Me is only stable up to $150^{\circ} \mathrm{C}$. EI-101 and EI-111-4Me show monophasic decomposition whereas EI-111, EI-111-2Me, EI-111-3Me show biphasic decomposition patterns. Initial

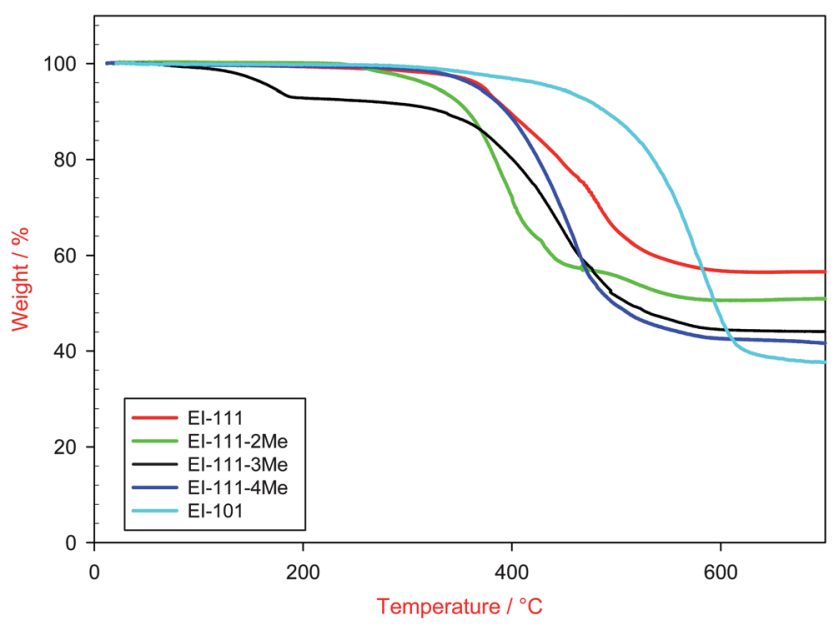

Fig. 3 Thermogravimetry of EI-101 (LiQ), EI-111, EI-111-2Me, EI-111$3 \mathrm{Me}, \mathrm{EI}-111-4 \mathrm{Me}$ under nitrogen atmosphere. 
Table 3 Thermal properties of electron injectors determined by DSC and TGA ${ }^{a}$

\begin{tabular}{|c|c|c|c|c|c|}
\hline Material & $T_{\mathrm{g}} /{ }^{\circ} \mathrm{C}$ & $T_{\mathrm{m}} /{ }^{\circ} \mathrm{C}$ & $T_{\mathrm{d}} /{ }^{\circ} \mathrm{C}$ at $1 \%$ mass $\operatorname{loss}^{c}$ & $T_{\mathrm{d}}{ }^{\circ} \mathrm{C}$ at $5 \%$ mass $\operatorname{loss}^{c}$ & $\begin{array}{l}\text { Initial decomposition } \\
\text { rate constant }\left(\mathrm{k} / \mathrm{s}^{-1}\right)\end{array}$ \\
\hline EI-101 (LiQ) & 130 & 367 & 320 & 420 & $3.3 \times 10^{-4}$ \\
\hline EI-111-2Me & $b$ & 249 & 260 & 327 & $2.0 \times 10^{-4}$ \\
\hline EI-111-3Me & $b$ & 240 & 126 & 174 & $2.8 \times 10^{-3}$ \\
\hline EI-111-4Me & $b$ & 318 & 317 & 371 & $5.7 \times 10^{-4}$ \\
\hline
\end{tabular}

${ }^{a} T_{\mathrm{g}}$ : glass transition temperature, $T_{\mathrm{m}}$ : melting point, $T_{\mathrm{d}}$ : decomposition temperature. ${ }^{b}$ No $T_{\mathrm{g}} \cdot{ }^{c}$ Under nitrogen atmosphere.

decomposition rates were calculated assuming first-order kinetics and the rate constant (see Table 3) for decomposition follows the order:

$$
\text { EI-111-2Me }<\text { EI-101 < EI-111-4Me }<\text { EI-111 < EI-111-3Me. }
$$

It is clear that EI-111-2Me is the most stable electron injector, followed by EI-101. The thermal evaporation characteristics under vacuum were found to be most stable for EI-111-2Me followed by EI-101: the others were unstable over extended periods ( 5 days at elevated temperatures) of evaporation under OLED manufacturing conditions, as measured by changes in vacuum pressure of over $10 \%$ (a change of over $10 \%$ in pressure over a period $24 \mathrm{~h}$ at the appropriate evaporation temperature is deemed to be unsuitable for OLED manufacturing). We attribute the lower stability of EI-111-3Me to the weakening of bond strength between the lone pair of nitrogen and the lithium atom due to the deactivating effect of the meta substituted methyl group and the possible difference in the stability of lithium clusters owing to steric effects.

Fig. 4 shows the evaporation rate $\left(\AA^{-1}\right) v s$. temperature at a pressure of $2 \times 10^{-5} \mathrm{~Pa}$. To give an evaporation rate of $0.2 \AA$ $\mathrm{s}^{-1}$, the temperature required for the electron injectors follows the order:

$$
\begin{aligned}
\text { EI-111-2Me }<\text { EI-111 }< & \text { EI-111-3Me }<\text { EI-111-4Me }<\text { EI-101 } \\
& (\text { LiQ })<\text { LiF }
\end{aligned}
$$

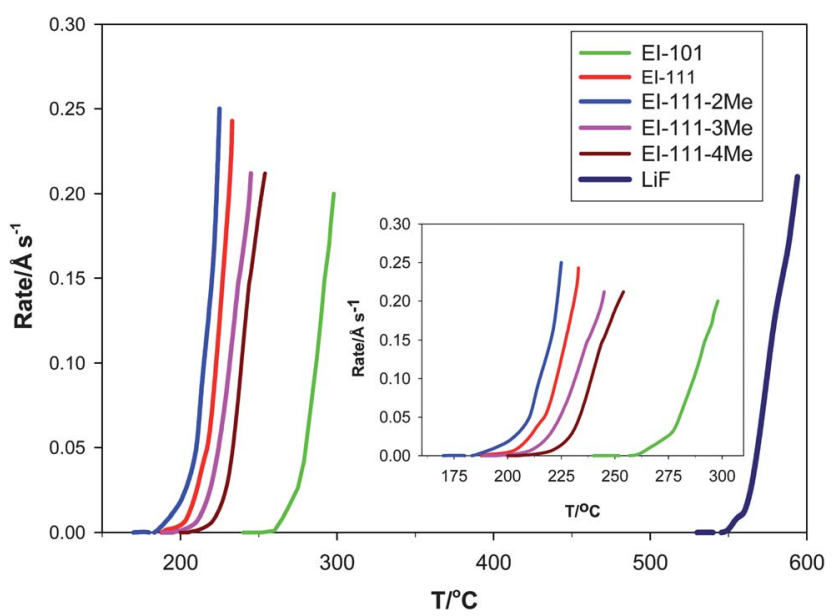

Fig. 4 Evaporation rate $\left(\AA \mathrm{s}^{-1}\right)$ vs. temperature $\left({ }^{\circ} \mathrm{C}\right)$ under vacuum $(2 \times 10-5 \mathrm{~Pa})$ in the Solciet, ULVAC, OLED production equipment.
Table 4 Evaporation temperatures at a pressure of $2 \times 10^{-5} \mathrm{~Pa}$

\begin{tabular}{ll}
\hline Material & $\begin{array}{l}\text { Evaporation temperature }\left({ }^{\circ} \mathrm{C}\right) \text { to } \\
\text { give an evaporation rate of } 0.2 \AA^{-1}\end{array}$ \\
\hline $\mathrm{LiF}$ & $590 \pm 10$ \\
$\mathrm{EI}-101(\mathrm{LiQ})$ & $296 \pm 2$ \\
EI-111 & $229 \pm 2$ \\
EI-111-2Me & $213 \pm 2$ \\
EI-111-3Me & $245 \pm 2$ \\
EI-111-4Me & $254 \pm 2$ \\
\hline
\end{tabular}

Typical temperatures required for evaporation under a vacuum of $2 \times 10^{-5} \mathrm{~Pa}$ are given in Table 4 .

Electrochemistry. Cyclic voltammetry was performed on all the complexes ( $1 \mathrm{mM}$ in freshly distilled acetonitrile) containing tetrabutylammonium tetrafluoroborate $\left(\mathrm{TBABF}_{4}(10 \mathrm{mM})\right)$ as a supporting electrolyte. The working, auxiliary and reference electrodes were Pt foil $\left(2 \mathrm{~cm}^{2}\right), \mathrm{Pt}$ (wire) and $\mathrm{Ag} / \mathrm{AgCl}$ respectively. The cyclic voltammetries in the reduction region $(0$ to $-2.0 \mathrm{~V} v s$. $\mathrm{Ag} / \mathrm{AgCl})$ were found to be irreversible whereas in the oxidation region $(0$ to $+2.0 \mathrm{~V})$, they were all quasi-reversible. We used cyclic voltammetry in the oxidation region to determine the HOMO levels (see Fig. 5). In all cases, two anodic peaks were observed at all scan rates. At high scan rates, one reduction peak

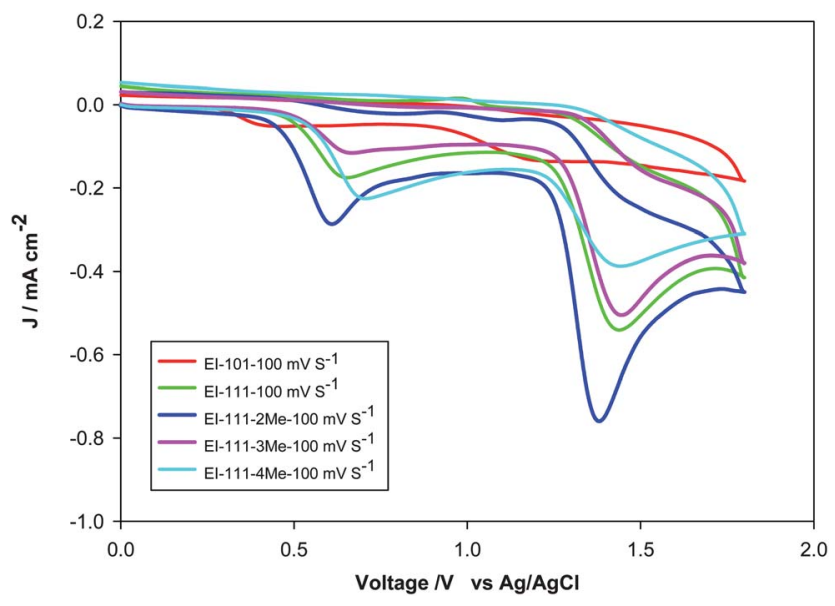

Fig. 5 Cyclic voltammetry at $100 \mathrm{mV} \mathrm{s}^{-1}$. Analyte: $1 \mathrm{mM}$ of EI-101 (LiQ), EI-111, EI-111-2Me, EI-111-3Me, EI-111-4Me. Supporting electrolyte: tetrabutylammonium tetrafluoroborate, working electrode: Pt, reference electrode: $\mathrm{Ag} / \mathrm{AgCl}$. 


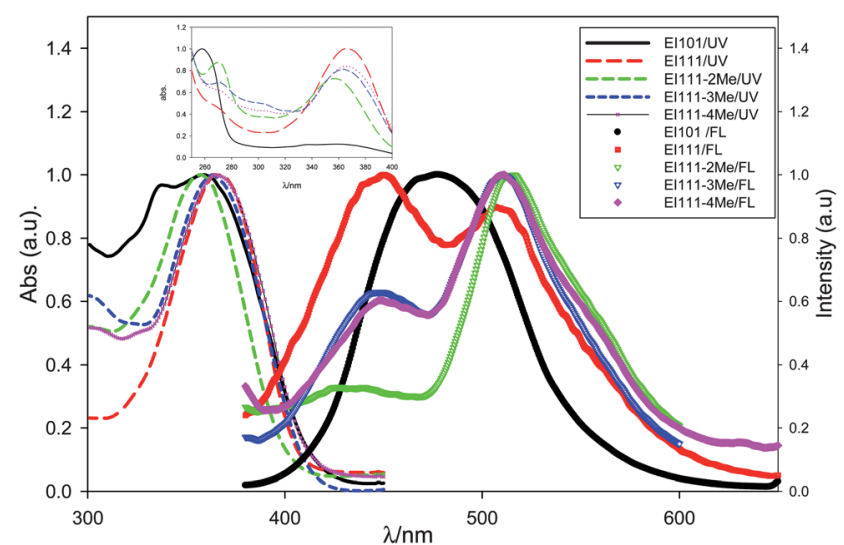

Fig. 6 Absorption and emission spectra of thin films of EI-101 (LiQ), EI-111, EI-111-2Me, EI-111-3Me, EI-111-4Me.

was also observed. It was established that both the peaks are diffusion controlled oxidation peaks by verifying that the peak currents had a linear relationship with the square root of scan rate $\left(i_{\mathrm{p}} \propto r^{1 / 2}\right)$. The HOMO levels were determined from the equation in ref. 33 :

$$
\mathrm{HOMO} \text { or } \mathrm{LUMO}=-\left(\left(E_{1 / 2} \text { vs. NHE }\right)+4.40\right) \mathrm{eV}
$$

where $\mathrm{NHE}=$ Normal Hydrogen Electrode. The $E_{1 / 2}$ values employed here were determined from the derivative of the cyclic voltammograms.

Optical characterisation. The absorption spectra as well as fluorescence spectra of vacuum-evaporated thin films of EI-101 (LiQ), EI-111, EI-111-2Me, EI-111-3Me and EI-111-4Me are shown in Fig. 6. Surprisingly, there were only small differences in the absorption maximum or absorption edge (band gap), but there are significant differences in the fluorescence spectra between EI-111-2Me and the parent and the 3- and 4-substituted compounds. LiQ shows only one emission peak whereas all the Schiff-base complexes show two emission peaks. These are summarised in Table 5. EI-111 has the highest emission intensity for the peak in the shorter wavelength and the intensity diminishes for the substituted compounds. EI-111-3Me and EI-111$4 \mathrm{Me}$ show nearly $40 \%$ lower intensity and EI-111-2Me shows nearly $70 \%$ reduction in intensity compared to the parent compound EI-111. The intensity of the fluorescence of the second peak (the longer wavelength peak) is similar.
Table 6 HOMO-LUMO levels and band gaps

\begin{tabular}{llll}
\hline Material & LUMO/eV & HOMO/eV & $E_{\mathrm{g}} / \mathrm{eV}$ \\
\hline EI-101 (LiQ) & $-2.00 \pm 0.01$ & $-5.00 \pm 0.01$ & $3.00 \pm 0.01$ \\
EI-111 & $-2.15 \pm 0.01$ & $-5.20 \pm 0.01$ & $3.05 \pm 0.01$ \\
EI-111-2Me & $-2.10 \pm 0.01$ & $-5.20 \pm 0.01$ & $3.1 \pm 0.01$ \\
EI-111-3Me & $-2.19 \pm 0.01$ & $-5.21 \pm 0.01$ & $3.02 \pm 0.01$ \\
EI-111-4Me & $-2.23 \pm 0.01$ & $-5.23 \pm 0.01$ & $3.00 \pm 0.01$ \\
EI-111-2F & $-3.20 \pm 0.01$ & $-6.10 \pm 0.01$ & $2.90 \pm 0.01$ \\
EI-111-3F & $-3.00 \pm 0.01$ & $-6.10 \pm 0.01$ & $3.10 \pm 0.01$ \\
EI-111-4F & $-3.40 \pm 0.01$ & $-6.30 \pm 0.01$ & $2.90 \pm 0.01$ \\
LiF (ref. 34) & -1.0 & -14.0 & 13.0 \\
Alq $_{3}$ (ref. 1) & $-2.90 \pm 0.01$ & $-5.70 \pm 0.01$ & $2,80 \pm 0.01$ \\
Zrq $_{4}$ (ref. 1) & $-2.94 \pm 0.01$ & $-5.62 \pm 0.01$ & $2.68 \pm 0.01$ \\
\hline
\end{tabular}

The first fluorescent peak (lower wavelength) for EI-111-2Me is blue-shifted by nearly 11-12 nm compared to EI-111, EI-1112Me and EI-111-3Me. Similarly, the absorption maximum for EI-111-2Me is blue-shifted by $7 \mathrm{~nm}$. We attribute this to the steric effect imparted by the methyl group which would be most prominent in the ortho position. Based on the HOMO levels and the band gap (absorption edge of the thin films), LUMO levels were deduced which are presented in Table 6 (see also Fig. 7) along with the HOMO-LUMO levels of $\mathrm{LiF}$ and $\mathrm{Alq}_{3}$ for reference.

We also synthesised fluorine-substituted analogues of the lithium complexes for the first time in order to examine the effect of the electronegative atoms on the HOMO-LUMO levels. The HOMO-LUMO levels of these complexes are compared with the methyl analogues in Table 6.

It is surprising to note that the HOMO levels of EI-111 and its methyl derivatives are the same and so the difference between the LUMO levels is small. Both the HOMO levels and the LUMO levels of EI-101 (LiQ) are raised with respect to the respective energy levels of EI-111 by 0.20 and $0.15 \mathrm{eV}$ respectively. Although it is well known that the substitution of electron withdrawing groups usually depresses the HOMO and LUMO levels, ${ }^{44}$ the lowering of the HOMO level on substituting an $\mathrm{F}$ atom for a methyl group by up to $1.1 \mathrm{eV}$ is remarkable. LUMO levels also drop by up to $1.2 \mathrm{eV}$ compared to the corresponding methyl-substituted analogues.

Electrical characterisation. The conductivity (DC and AC) and the permittivity of the materials were measured on compacted discs (two probe method). ${ }^{35}$ The conductivity of the complexes was so low $\left(<1 \times 10^{-8} \mathrm{~S} \mathrm{~cm}^{-1}\right)$ that four probe measurements could not be carried out. ${ }^{47-51}$ The data are summarised in Table 7.

Table 5 Optical properties: absorption maximum, absorption edge, band gap, fluorescence maxima and fluorescence band gap ${ }^{a}$

\begin{tabular}{llllll}
\hline Material & $\begin{array}{l}\text { Absorption } \\
\text { maximum }\left(\lambda_{\max } \mathrm{nm}^{-1}\right)\end{array}$ & $\begin{array}{l}\text { Absorption } \\
\text { edge }\left(\lambda_{\text {edge }} \mathrm{nm}^{-1}\right)\end{array}$ & Band gap/eV & $\begin{array}{l}\text { Fluorescence } \\
\text { maxima }\left(\lambda_{\text {max }} \mathrm{nm}^{-1}\right)\end{array}$ & $\begin{array}{l}\text { Fluorescence } \\
\text { band gaps/eV }\end{array}$ \\
\hline EI-101 (LiQ) & $359 \pm 2$ & $413 \pm 2$ & $3.00 \pm 0.01$ & 477 & $2.60 \pm 0.01$ \\
EI-111 & $367 \pm 2$ & $407 \pm 2$ & $3.05 \pm 0.01$ & $448(\mathrm{~s}), 509(\mathrm{~s})$ & $2.77 \pm 0.01,2.44 \pm 0.01$ \\
EI-111-2Me & $357 \pm 2$ & $400 \pm 2$ & $3.10 \pm 0.01$ & $436(\mathrm{w}), 516(\mathrm{~s})$ & $2.84 \pm 0.01,2.40 \pm 0.01$ \\
EI-111-3Me & $364 \pm 2$ & $410 \pm 2$ & $3.02 \pm 0.01$ & $447(\mathrm{w}), 509(\mathrm{~s})$ & $2.77 \pm 0.01,2.44 \pm 0.01$ \\
EI-111-4Me & $366 \pm 2$ & $413 \pm 2$ & $3.00 \pm 0.01$ & $448(\mathrm{~m}), 509(\mathrm{~s})$ & $2.77 \pm 0.01,2.44 \pm 0.01$
\end{tabular}

${ }^{a}(\mathrm{~s})$ : Strong, (m): medium, (w): weak intensity. 


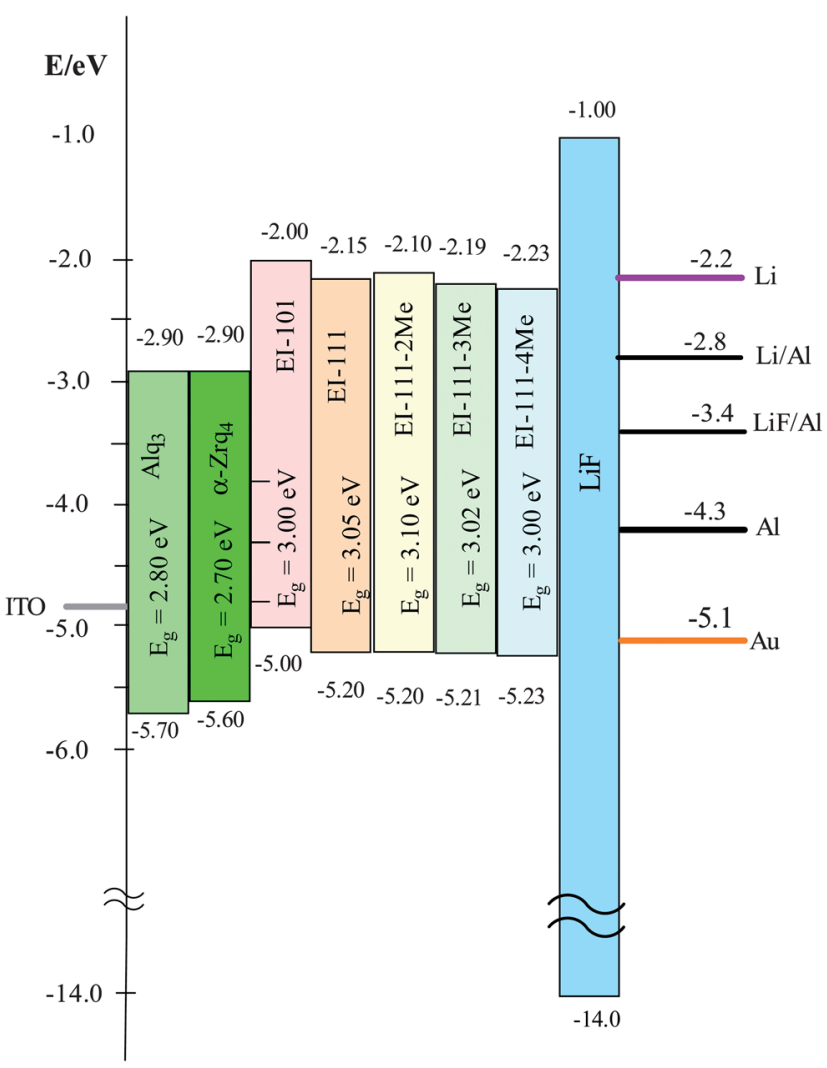

Fig. 7 HOMO-LUMO levels of $\mathrm{Alq}_{3}, \mathrm{Zrq}_{4}$, EI-101 (LiQ), EI-111, EI111-2Me, EI-111-3Me, EI-111-4Me and LiF.

The DC conductivity of the compacted discs follows the order EI-101 $>$ EI-111-2Me $>$ EI-111-3Me $>$ EI-111-4Me $>$ Alq $_{3}>$ EI111, while the AC conductivity follows the order EI-111-4Me $>$ EI-111-3Me $>$ EI-111-2Me $>\mathrm{Alq}_{3}>$ EI-111 $>$ EI-101. The AC conductivities are up to 4000 -fold higher than the corresponding DC conductivities.

The electron and hole mobilities were determined from electron-only (Li-Al/EI/Li-Al, System A) and hole-only (ITO/EI/ $\mathrm{Au}$, System D), devices respectively, from the current density vs. voltage plots of these thin film devices. The energy level diagram for the single-layer devices under unbiased condition is shown in Fig. 7. Only EI-101, EI-111, EI-111-2Me devices were investigated in this study as the preliminary data indicated that the lifetimes of OLED devices with EI-111-3Me, EI-111-4Me, EI111-2F, EI-111-3F and EI-111-4F as electron injectors were very short and therefore no further experiments were carried out on these materials.

The current density $\left(J_{\mathrm{d}} / \mathrm{mA} \mathrm{cm}^{-2}\right)$ vs. field $\left(E / \mathrm{V} \mathrm{cm}^{-1}\right)$ for the electron-only devices and hole-only devices are shown in Fig. 8 and 9 , respectively. We fitted these data to diode, tunnelling

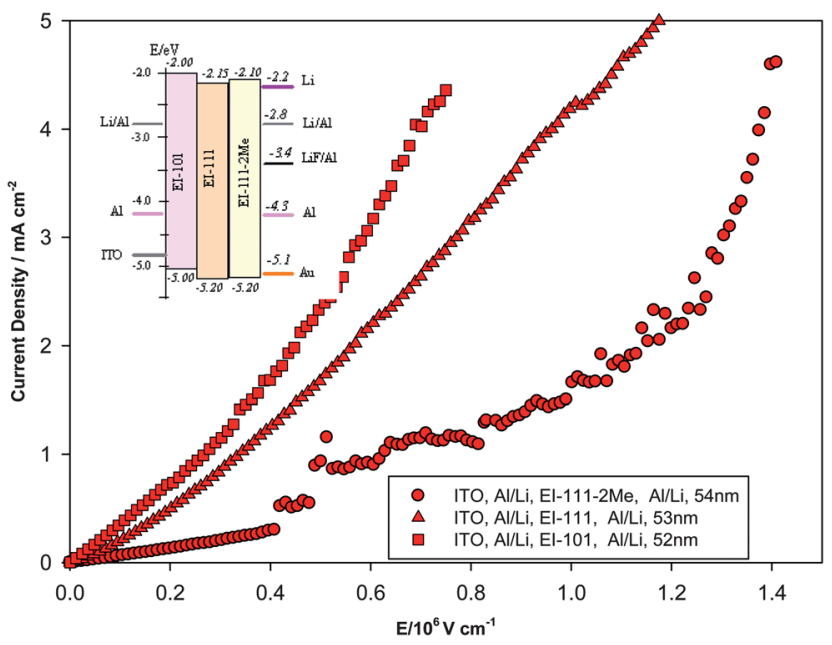

Fig. 8 Electron-only devices: Li-Al/EI/Li-Al where EI: EI-101 (LiQ), EI-111, EI-111-2Me. Current density $\left(\mathrm{mA} \mathrm{cm}^{-2}\right) v s$. field $\left(\mathrm{V} \mathrm{cm}^{-1}\right)$.

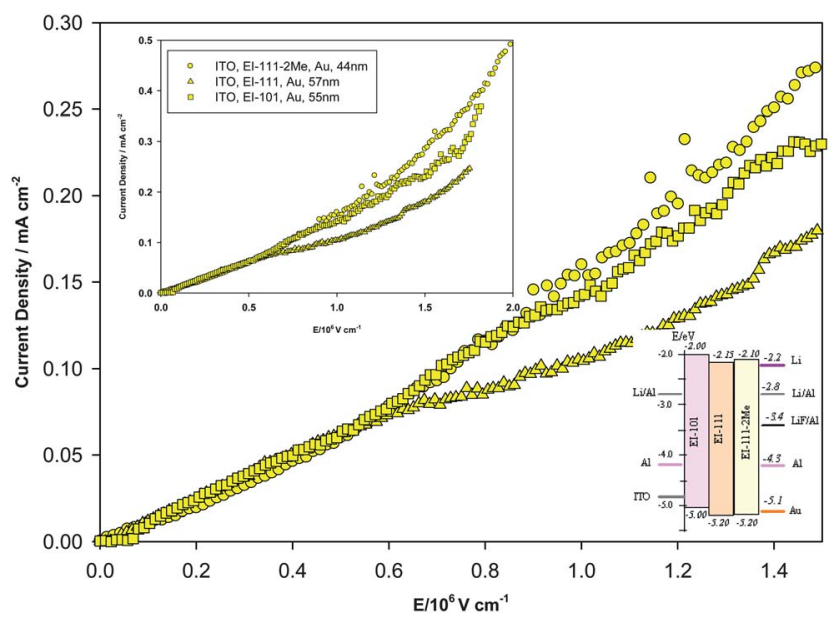

Fig. 9 Hole-only devices: ITO/EI/Au where EI: EI-101 (LiQ), EI-111, EI-111-2Me. Current density $\left(\mathrm{mA} \mathrm{cm}^{-2}\right) v s$. field $\left(\mathrm{V} \mathrm{cm}^{-1}\right)$.

(Fowler Nordheim) and SCLC models ${ }^{36-40}$ and found that the data fitted well to the SCLC model but not to the others.

The magnitude of current density for any given field is much higher for the electron-only devices compared with the corresponding hole-only devices for all the materials considered herein, namely EI-101 (LiQ), EI-111 and EI-111-2Me. The current density $\left(J_{\mathrm{d}} / \mathrm{mA} \mathrm{cm}^{-2}\right) v s$. field $\left(E / \mathrm{V} \mathrm{cm}^{-1}\right)$ plots for the electron-only devices (Fig. 8) show that the electron injection follows the order EI-101 (LiQ) > EI-111> EI-111-2Me. However, hole-only devices follow the order EI-111-2Me $\geq$

Table 7 DC and AC conductivity $(100 \mathrm{kHz})$ and relative permittivity

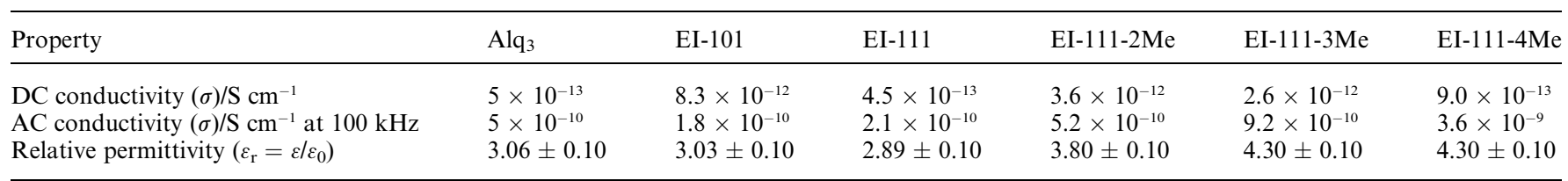


Table 8 Thin film conductivity, electron and hole mobilities and charge carrier density

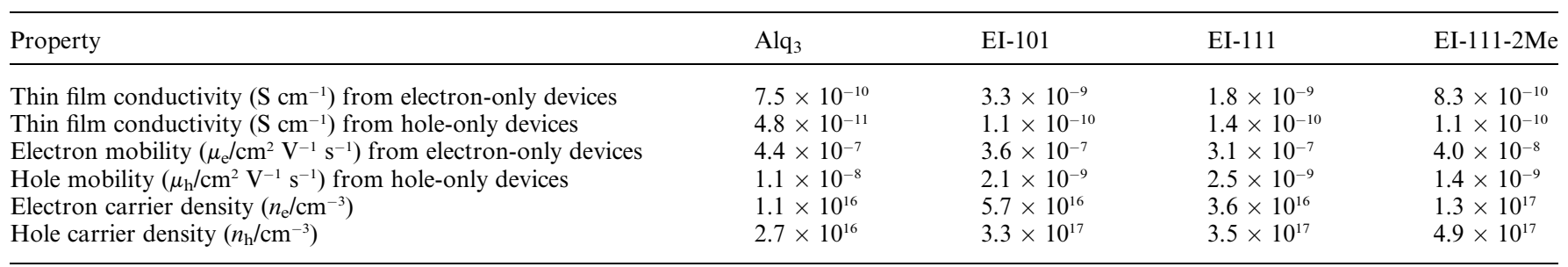

EI-101 $>$ EI-111 at high fields $\left(E>5 \times 10^{5} \mathrm{~V} \mathrm{~cm}^{-1}\right)$ and at low fields they are identical within experimental error.

Thin film conductivity was determined from the Ohmic region $\left(J_{\mathrm{d}} \propto V\right)$ and the mobility was calculated from the space charge region $\left(J_{\mathrm{d}} \propto V^{2}\right)$ using the equation:

$$
J_{\mathrm{SCLC}}=(9 / 8) \varepsilon \mu V^{2} / d^{3}
$$

where $J_{\mathrm{SCLC}}=$ current density in the SCLC region, $\varepsilon=$ permittivity, $\mu=$ mobility, $V=$ voltage and $d=$ thickness. The data obtained from the hole-only and electron-only devices are summarized in Table 8 .

There is a significant difference in conductivities of up to 1000fold between the vacuum thermal evaporated thin films and the compacted discs: this is attributed to the morphology and the nature of packing in the thin films where we expect the molecular orientation to affect the electrical and electronic properties (anisotropic conductivity and mobility) compared to the isotropic packing in the bulk compacted powders. ${ }^{1,45,46}$

Several features are immediately obvious from Table 8:

(i) The thin film conductivity of EI-101 is higher than that of EI-111 and EI-111-2Me (EI-101 > EI-111 > EI-111-2Me) for the electron-only devices. The electron mobility follows the same order.

(ii) The degree of anisotropy (conductivity of the thin film/ conductivity of the disc) is 4000 for EI-111, 398 for EI-101 and 230 for EI-111-2Me.

(iii) The hole mobilities of all the electron injector materials studied here are comparable.

The question is whether the reduction in operating voltage by $\mathrm{LiF}$ or LiQ (EI-101) is due to the reaction with the thermally evaporated reactive aluminium atoms with the lithium compounds, thereby producing elemental lithium as proposed by Kido et al., ${ }^{10,17}$ where $\mathrm{Alq}_{3}$ is an electron transporter,

$$
3 \mathrm{LiF}+\mathrm{Al}+3 \mathrm{Alq}_{3} \rightarrow \mathrm{AlF}_{3}+3 \mathrm{Li}^{+} \mathrm{Alq}_{3}{ }^{-}
$$

If this were true, then any lithium complex should provide a reduction in the operating voltage as free $\mathrm{Li}$ atoms are produced on reaction with $\mathrm{Al}$, thereby reducing the work function of the organics (electron transporter)/Al electrode interface.

Thus, we reasoned that single-layer devices made of the lithium complexes of EI-101 (LiQ), EI-111 and EI-111-2Me with Li-Al electrodes (System A, Fig. 8) should produce the same order of current density as for the devices Al/EI/Al (Fig. 10, System B) for a given field. To test this principle, we fabricated devices of EI-101, EI-111 and EI-111-2Me having aluminium as top and bottom contacts by vacuum thermal evaporation (VTE). First, a relatively thick layer of aluminium (200 nm) was

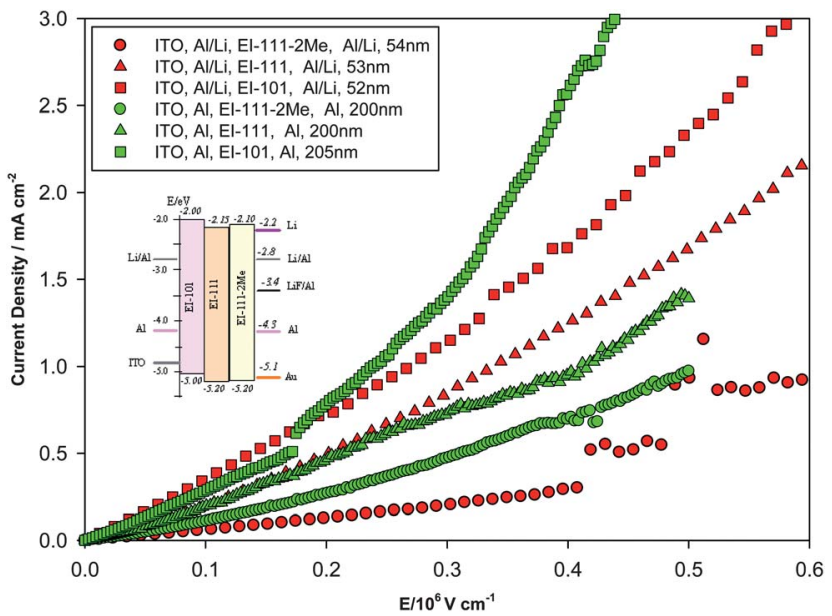

Fig. 10 Comparison of electron-only devices $\mathrm{Li}-\mathrm{Al} / \mathrm{EI} / \mathrm{Li}-\mathrm{Al}$ with Al/EI/Al where EI: EI-101 (LiQ), EI-111, EI-111-2Me.

evaporated onto ITO/glass, then an electron injector was evaporated, followed by aluminium top contact of approximately $200 \mathrm{~nm}$.

Consistent with our expectation, the current density for the devices with aluminium top and bottom contacts was comparable to that of the devices with $\mathrm{Li}-\mathrm{Al}$ (top and bottom) contacts. This clearly indicates that either energetic aluminium atoms, or surface or energetic lithium complexes on $\mathrm{Al}$, are sufficient to produce a low work function metal alloy-like ( $\mathrm{Li}-\mathrm{Al}$ type) behaviour with concomitant lowering of the barrier for injection of electrons. This is an important finding as it paves the way for the production of OLEDs with an inverted device structure, namely starting with an aluminium film electrode onto a silicon backplane or stainless steel electrode for flexible display applications. Another possibility is the enhancement of conductivity as a result of the production of charge transfer complexes of the type $\mathrm{Li}^{+} \mathrm{Alq}_{3}{ }^{-}$.

For our electron injectors, we propose similar reactions consistent with Li et al. $^{26}$

$$
\mathrm{Al}+6 \mathrm{LiL} \rightarrow \mathrm{AlL}_{3}+3\left\{\mathrm{Li}^{+}(\mathrm{LiL})^{-}\right\}
$$

To further ascertain that the aluminium on the ITO is indeed required to produce the low work function contact to the electron injector, we fabricated devices of the type (ITO/EI/Al, System C, Fig. 11) to establish that the current density is much smaller than for system $\mathrm{B}(\mathrm{Al} / \mathrm{EI} / \mathrm{Al})$. Table 9 summarises the current density at $5 \times 10^{5} \mathrm{~V} \mathrm{~cm}^{-1}$ for all the electrode systems investigated. 


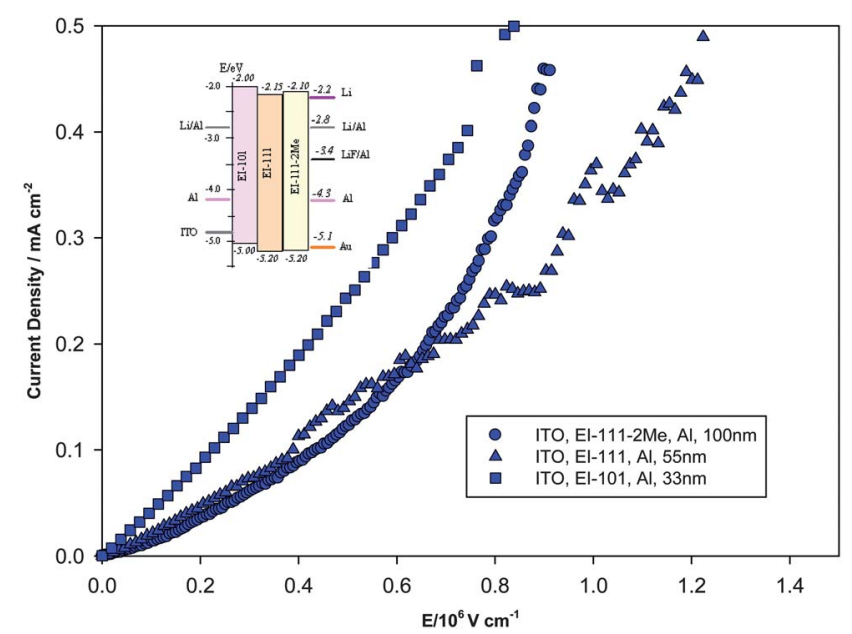

Fig. 11 Single-layer mixed-carrier devices: ITO/EI/Al where EI: EI-101 (LiQ), EI-111, EI-111-2Me.

The current density of $\mathrm{Al} / \mathrm{EI} / \mathrm{Al}$ is either higher than or comparable to $\mathrm{Li}-\mathrm{Al} / \mathrm{EI} / \mathrm{Li}-\mathrm{Al}$, confirming the fact that $\mathrm{Li}$ is produced at the interface as suggested by Kido et al. ${ }^{10,17}$

We fabricated mixed-carrier single-layer devices of ITO/EI/Al. At low field $\left(E<1 \times 10^{6} \mathrm{~V} \mathrm{~cm}^{-1}\right)$, the $J_{\mathrm{d}}$ follows the order EI-101 $>$ EI-111-2Me $>$ EI-111 whilst at high field $\left(E>1.5 \times 10^{6} \mathrm{~V}\right.$ $\mathrm{cm}^{-1}$ ), the order of current injection changes to EI-111-2Me $>$ EI-111 > EI-101. The current densities of the ITO/EI/Al devices (dual carrier transport) are higher than those of the hole-only devices, namely, ITO/EI/Au as expected.

Green devices. Green devices of ITO (40 $\Omega$ per square)/ ZnTPTP $(20 \mathrm{~nm}) / / \alpha-\mathrm{NPB} \quad(50 \mathrm{~nm}) / \mathrm{Alq}_{3}$ : DPQA $(40 \mathrm{~nm}$ : $0.1 \mathrm{~nm}) / \mathrm{Zrq}_{4}(20 \mathrm{~nm}) / \mathrm{EI}(1 \mathrm{~nm}) / \mathrm{Al}$ were fabricated using the Solciet OLED Pilot Plant equipment purchased from ULVAC, Japan. The energy level diagram for the device under zero bias is depicted in Fig. 13.

The current density $\left(J_{\mathrm{d}}\right) v s$. voltage $(V)$ plots (Fig. 12) show that the EI-111 has the highest current injection followed by EI111-2Me, EI-101 and LiF (EI-111 > EI-111-2Me > EI-101 > LiF) despite the fact that the electron-only single-layer devices show that the current injection is highest for EI-101 (Fig. 8). We explain this difference on the basis that these multilayer light emitting devices are operating under mixed-carrier conduction and the interface between the $\mathrm{Zrq}_{4}$ and the electron injector would have substantial influence. We postulate that there is also the possibility of the formation of a charge transfer complex of formula $\mathrm{Li}^{+}\left(\mathrm{Zrq}_{4} \mathrm{~L}\right)^{-}$which could act as a dipole just like $\mathrm{LiF}$ on diamond ${ }^{21}$ and thus enhance carrier injection. The luminance $\left(L / \mathrm{cd} \mathrm{m}^{-2}\right)$ vs. voltage (Fig. 13) simply follows the same pattern as
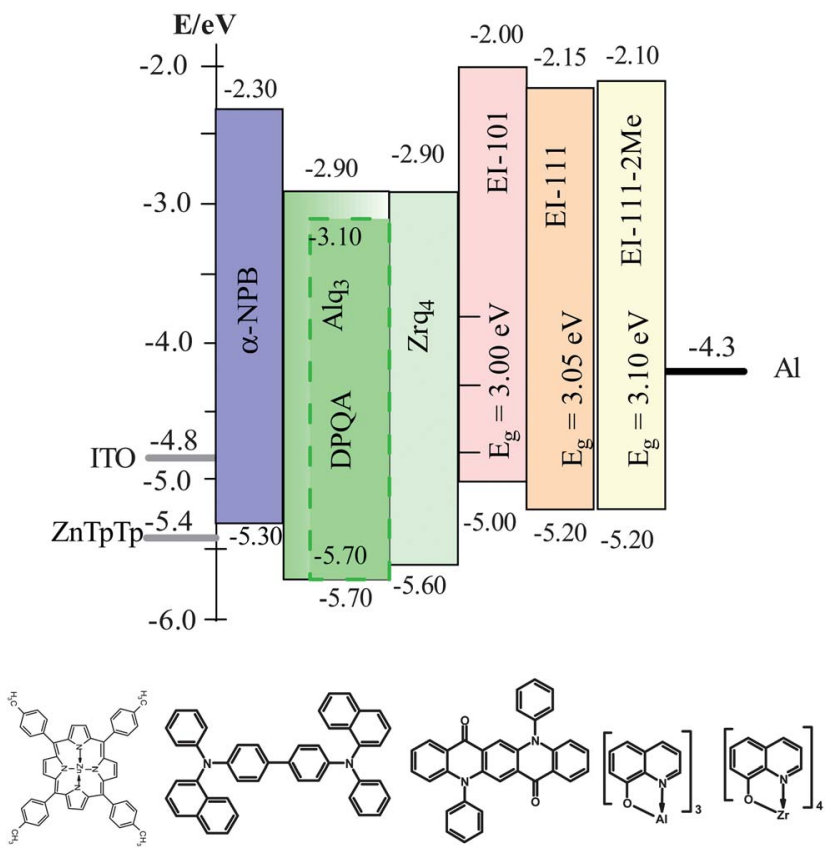

Fig. 12 HOMO-LUMO energy levels for ZnTPTP (hole injector), $\alpha$-NPB (hole transporter), $\mathrm{Alq}_{3}$ (host), DPQA (--- green dopant), $\mathrm{Zrq}_{4}$ (electron transporter), EI (electron injector) where EI: EI-101 (LiQ), EI-111, EI-111-2Me.

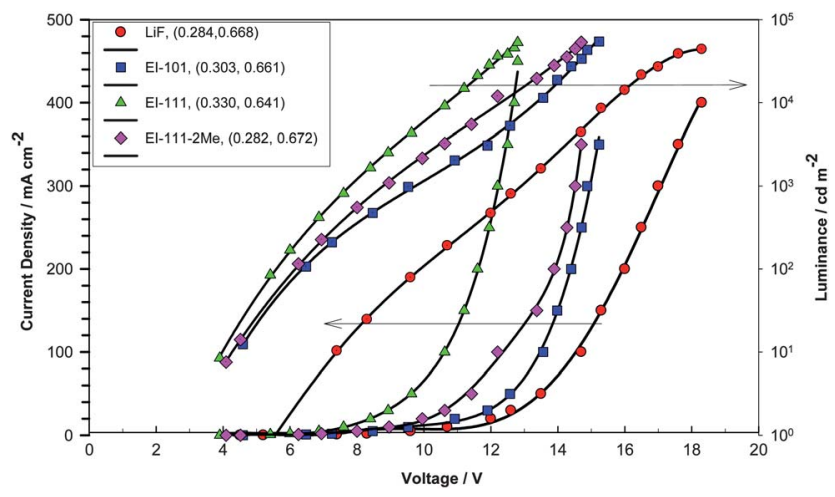

Fig. 13 Current density-voltage-luminance characteristics of ITO/ ZnTPTP $(20 \mathrm{~nm}) / \alpha-\mathrm{NPB}(50 \mathrm{~nm}) / \mathrm{Alq}_{3}$ : DPQA $(40: 0.1 \mathrm{~nm}) / \mathrm{Zrq}_{4}$ $(20 \mathrm{~nm}) / \mathrm{EI}(1 \mathrm{~nm}) / \mathrm{Al}$ where EI: LiF, EI-101 (LiQ), EI-111, EI-111-2Me.

the $J_{\mathrm{d}} v s . \quad V$. The electroluminescence spectra are shown in Fig. 14. The slight differences in the spectra and the consequent colour co-ordinates are attributed to minor variation in the dopant concentration. The turn-on voltages (to give a luminance of $1 \mathrm{~cd} \mathrm{~m}^{-2}$ ) for EI-111, EI-111-2Me, EI-101 and LiF are 3.0, 3.2,

Table 9 Current density at a field of $5 \times 10^{5} \mathrm{~V} \mathrm{~cm}^{-1}$ for electron-only and hole-only devices

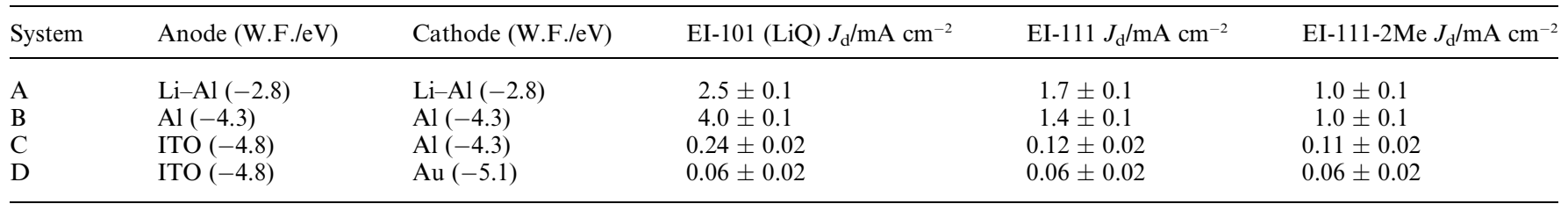




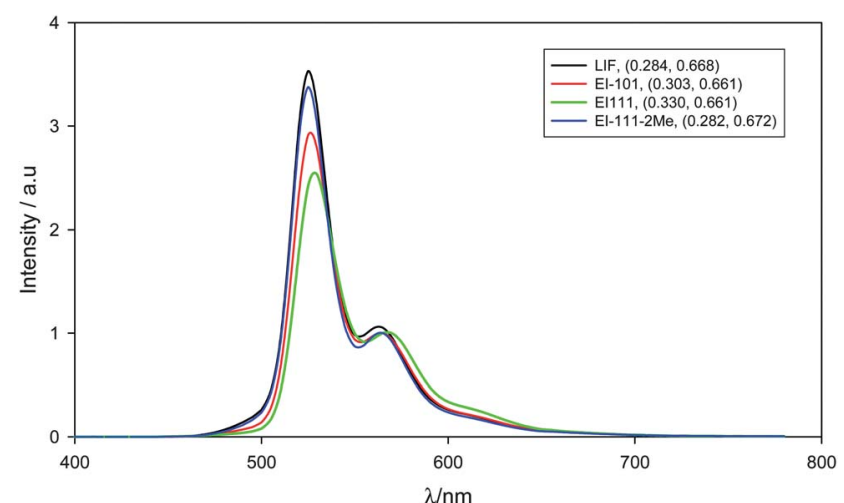

Fig. 14 Electroluminescence spectra of ITO/ZnTPTP $(20 \mathrm{~nm}) / \alpha$-NPB $(50 \mathrm{~nm}) / \mathrm{Alq}_{3}:$ DPQA $(40: 0.1 \mathrm{~nm}) / \mathrm{Zrq}_{4}(20 \mathrm{~nm}) / \mathrm{EI}(1 \mathrm{~nm}) / \mathrm{Al}$ where EI: LiF, EI-101 (LiQ), EI-111, EI-111-2Me at $1000 \mathrm{~cd} \mathrm{~m}^{-2}$.

3.4 and 4.0 V (Table 10). On replacing LiF as an electron injector, the operating voltage at $1000 \mathrm{~cd} \mathrm{~m}^{-2}$ drops from $12.8 \mathrm{~V}$ to $9.8 \mathrm{~V}$ for EI-101, 8.8 V for EI-111-2Me and 7.8 V for EI-111.

The current efficiency $\left(\eta_{\mathrm{i}} / \mathrm{cd} \mathrm{\textrm {A } ^ { - 1 } )} v s\right.$. luminance $\left(\mathrm{cd} \mathrm{\textrm {m } ^ { - 2 }}\right)$ (Fig. 15) follows the order EI-111-2Me $>$ EI-101 > EI-111 > LiF. On replacing $\mathrm{LiF}$ with $\mathrm{EI}-111-2 \mathrm{Me}$, the current efficiency at $1000 \mathrm{~cd} \mathrm{~m}^{-2}$ increases from $6.5 \mathrm{~cd} \mathrm{~A}^{-1}$ to $11 \mathrm{~cd} \mathrm{~A}^{-1}$, an increase of nearly $69 \%$, and the corresponding power efficiency from 2.5 to $4.5 \mathrm{~lm} \mathrm{~W}^{-1}$, an increase of $80 \%$. This dramatic increase is attributed to enhanced electron injection from EI-111-2Me.

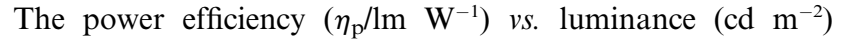
(Fig. 16) follows the same order as the current efficiency. On replacing $\mathrm{LiF}$ with EI-111-2Me, the power efficiency is doubled from 3 to $6 \mathrm{~lm} \mathrm{~W}^{-1}$ (Table 10).

The lifetime measurements were carried out at constant current at an initial luminance of 1029, 1046, 1052 and $1194 \mathrm{~cd} \mathrm{~m}^{-2}$ for LiF, EI-101, EI-111 and EI-111-2Me, respectively.

The luminance $\left(\mathrm{cd} \mathrm{m}^{-2}\right)$ vs. time (h) plots (Fig. 17) were fitted to the equation

$$
\text { Normalised luminance }\left(L / L_{0}\right)=\left[a \mathrm{e}^{(-\alpha t)}+b \mathrm{e}^{(-\beta t)}\right]
$$

for the electron injectors studied here.

The $a, b, \alpha$ and $\beta$ values are summarised in Table 11 .

The luminance decay curves for LiF, EI-101, EI-111-2Me have at least two phases, with the first being about 100 times faster than the second. The lowest $\beta$ value for EI-111-2Me clearly shows that EI-111-2Me decays most slowly amongst the electron injectors studied despite its initial fast decay (high $\alpha$ value). It should be noted that all OLED devices in general show

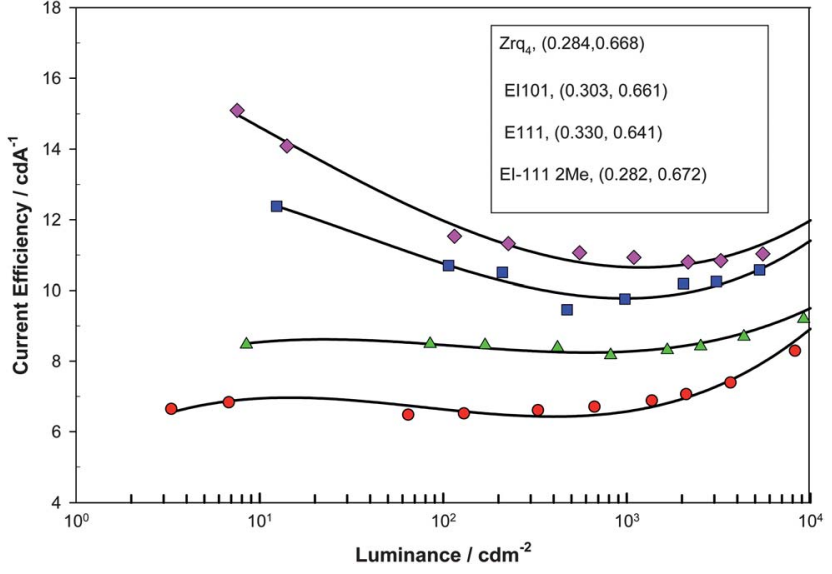

Fig. 15 Current efficiency $\left(\mathrm{cd} \mathrm{A}^{-1}\right)$ vs. luminance $\left(\mathrm{cd} \mathrm{m}^{-2}\right)$ characteristics of ITO/ZnTPTP $(20 \mathrm{~nm}) / \alpha-\mathrm{NPB}(50 \mathrm{~nm}) / \mathrm{Alq}_{3}$ : DPQA $(40: 0.1 \mathrm{~nm}) /$ $\mathrm{Zrq}_{4}(20 \mathrm{~nm}) / \mathrm{EI}(1 \mathrm{~nm}) / \mathrm{Al}$ where EI: LiF, EI-101 (LiQ), EI-111, EI-111-2Me.

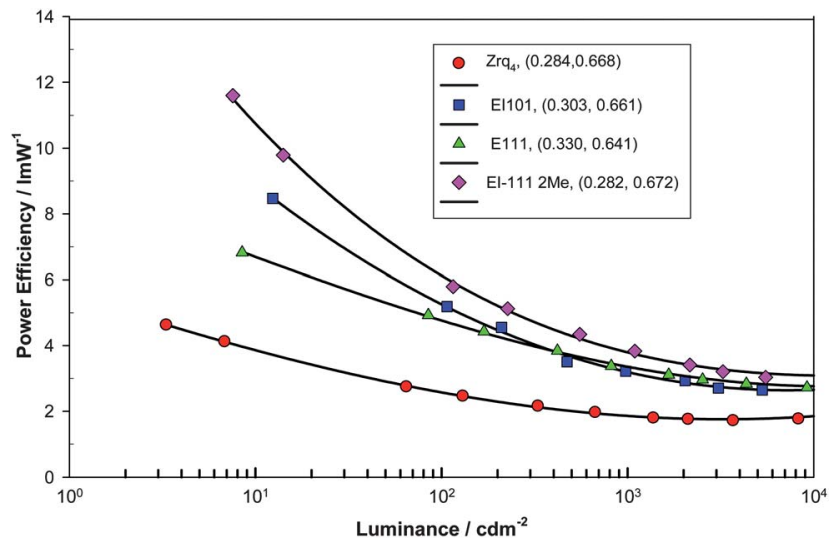

Fig. 16 Power efficiency $\left(\mathrm{lm} \mathrm{W}^{-1}\right)$ vs. luminance $\left(\mathrm{cd} \mathrm{m}^{-2}\right)$ characteristics of ITO/ZnTPTP $(20 \mathrm{~nm}) / \alpha-\mathrm{NPB}(50 \mathrm{~nm}) / \mathrm{Alq}_{3}$ : DPQA $(40: 0.1 \mathrm{~nm}) /$ $\mathrm{Zrq}_{4}(20 \mathrm{~nm}) / \mathrm{EI}(1 \mathrm{~nm}) / \mathrm{Al}$ where EI: LiF, EI-101 (LiQ), EI-111, EI-111-2Me.

substantial initial decay (aging) due to the ITO/hole injector junction interfacial changes. The later stages of the decay are generally regarded as originating from the electron transporter/ electron injector/metal cathode interface. ${ }^{9}$

Monitoring the voltage drift (Fig. 18) while driving the device (during the lifetime measurements, the initial luminance for LiF, EI-101, EI-111 and EI-111-2Me are 1029, 1046, 1052

Table 10 Green device performance: turn-on voltage, operating voltage, current efficiency, power efficiency and CIE colour co-ordinates at 1000 cd $\mathrm{m}^{-2}$

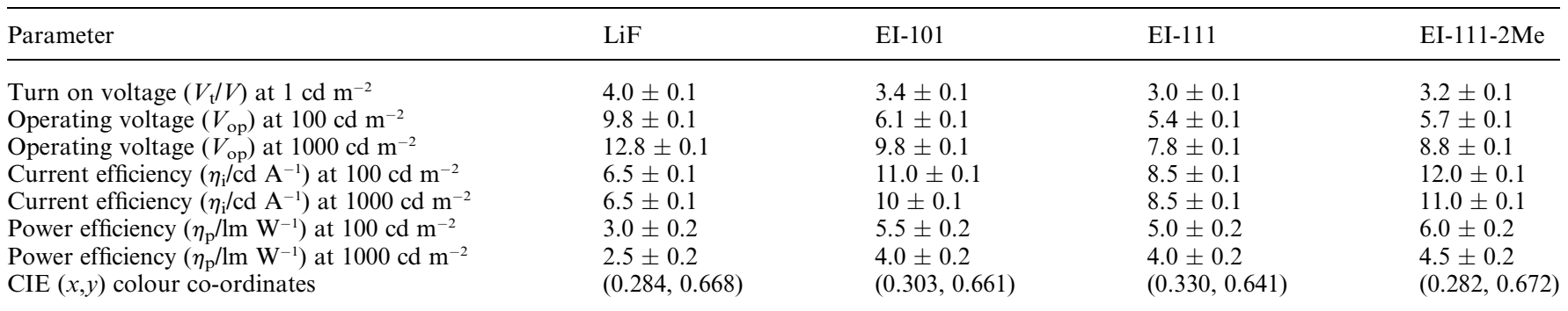




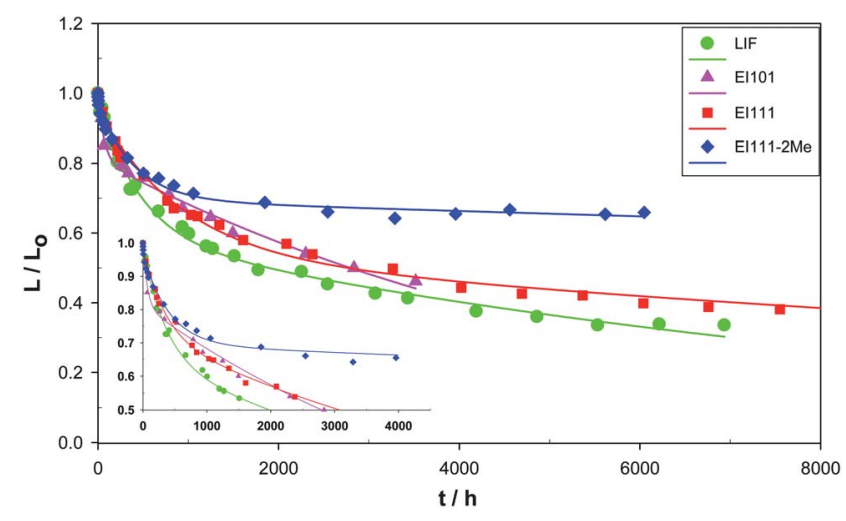

Fig. 17 Lifetime plots for ITO/ZnTPTP $(20 \mathrm{~nm}) / \alpha$-NPB $(50 \mathrm{~nm}) /$ $\mathrm{Alq}_{3}:$ DPQA $(40: 0.1 \mathrm{~nm}) / \mathrm{Zrq}_{4}(20 \mathrm{~nm}) / \mathrm{EI}(1 \mathrm{~nm}) / \mathrm{Al}$ where EI: LiF, EI101 (LiQ), EI-111, EI-111-2Me. Initial luminance: $1029 \mathrm{~cd} \mathrm{~m}^{-2}$ for LiF, 1046 $\mathrm{cd} \mathrm{m}^{-2}$ for EI-101, $1052 \mathrm{~cd} \mathrm{~m}^{-2}$ for EI-111 and $1194 \mathrm{~cd} \mathrm{~m}^{-2}$ for EI-111-2Me.

Table 11 Luminance $v s$. time curve fitting parameters for the equation $\left(L / L_{0}\right)=\left[a \mathrm{e}^{(-\alpha t)}+b \mathrm{e}^{(-\beta t)}\right]$

\begin{tabular}{lllll}
\hline Parameters & LiF & EI-101 & EI-111 & EI-111-2Me \\
\hline$a$ & 0.390 & 0.191 & 0.416 & 0.277 \\
$b$ & 0.593 & 0.812 & 0.539 & 0.695 \\
$\alpha / \mathrm{h}^{-1}$ & $2.2 \times 10^{-3}$ & $1.52 \times 10^{-2}$ & $1.11 \times 10^{-3}$ & $2.5 \times 10^{-3}$ \\
$\beta / \mathrm{h}^{-1}$ & $9.7 \times 10^{-5}$ & $2.0 \times 10^{-4}$ & $4.2 \times 10^{-5}$ & $1.2 \times 10^{-5}$ \\
Coefficient of & 0.9946 & 0.9904 & 0.9920 & 0.9878 \\
correlation & & & & \\
\hline
\end{tabular}

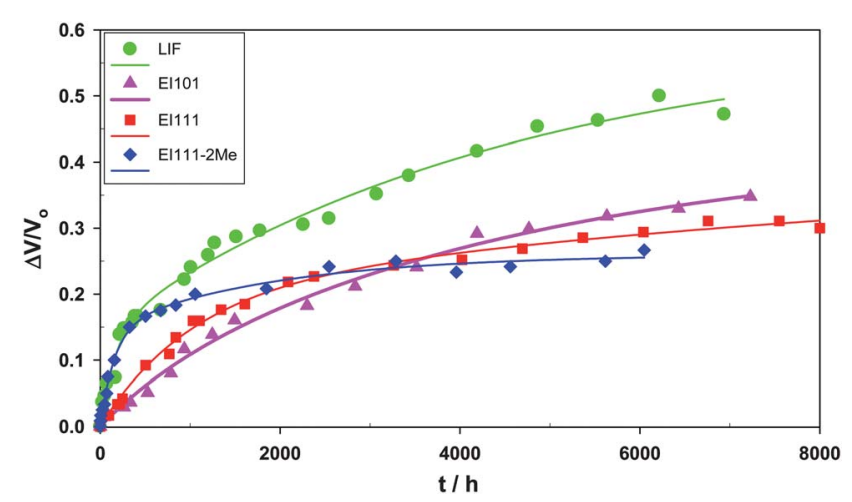

Fig. 18 Voltage drift for ITO/ZnTPTP $(20 \mathrm{~nm}) / \alpha$-NPB $(50 \mathrm{~nm}) /$ $\mathrm{Alq}_{3}: \mathrm{DPQA}(40: 0.1 \mathrm{~nm}) / \mathrm{Zrq}_{4}(20 \mathrm{~nm}) / \mathrm{EI}(1 \mathrm{~nm}) / \mathrm{Al}$ where EI: LiF, EI101 (LiQ), EI-111, EI-111-2Me. Initial luminance: $1029 \mathrm{~cd} \mathrm{~m}^{-2}$ for $\mathrm{LiF}$, $1046 \mathrm{~cd} \mathrm{~m}^{-2}$ for EI-101, $1052 \mathrm{~cd} \mathrm{~m}^{-2}$ for EI-111 and $1194 \mathrm{~cd} \mathrm{~m}^{-2}$ for EI-111$2 \mathrm{Me}$.

and $1194 \mathrm{~cd} \mathrm{~m}^{-2}$ respectively), there is clear evidence that EI-111$2 \mathrm{Me}$ gives the lowest drift voltage (most stable performance) over an extended period of time despite the initial rapid increase in voltage in the first 1000 hours. For example, over 4000 hours the voltage drift for EI-111-2Me, EI-111, EI-101 and LiF was found to be $0.25,0.27,0.28$ and $0.42 \mathrm{~V}$, respectively.

The voltage drift was fitted to the equation

$$
\Delta V=c\left(1-\mathrm{e}^{-\gamma t}\right)+d\left(1-\mathrm{e}^{-\delta t}\right)
$$

and the values obtained for $c, d, \gamma$ and $\delta$ are summarised in Table 12 .
Table 12 Drift voltage $v s$. time curve fitting parameters for the equation, $\Delta V=c\left(1-\mathrm{e}^{-\gamma t}\right)+d\left(1-\mathrm{e}^{-\delta t}\right)$

\begin{tabular}{lllll}
\hline Parameters & LiF & EI-101 & EI-111 & EI-111-2Me \\
\hline$c$ & 0.145 & 0.050 & 0.203 & 0.146 \\
$d$ & 0.45 & 0.376 & 0.220 & 0.110 \\
$\gamma / \mathrm{h}^{-1}$ & $5.7 \times 10^{-3}$ & $1.2 \times 10^{-3}$ & $1.0 \times 10^{-3}$ & $6.3 \times 10^{-3}$ \\
$\delta / \mathrm{h}^{-1}$ & $2.0 \times 10^{-4}$ & $2.0 \times 10^{-4}$ & $8.6 \times 10^{-5}$ & $5.0 \times 10^{-4}$ \\
Coefficient of & 0.9894 & 0.9930 & 0.9956 & 0.9942 \\
correlation & & & & \\
\hline
\end{tabular}

Table 13 The lifetime data [half-life $\left(t_{1 / 2}\right)$ ] and the normalised drift voltage performance data from all the green devices tested

\begin{tabular}{lllll}
\hline Parameter & LiF & EI-101 & EI-111 & EI-111-2Me \\
\hline $\begin{array}{l}\text { Initial } \\
\text { luminance } / \mathrm{cd} \mathrm{m}^{-2}\end{array}$ & 1029 & 1046 & 1052 & 1194 \\
$\begin{array}{l}\text { Life-time }\left(t_{1 / 2}\right) / \mathrm{h} \\
\text { Voltage drift }\end{array}$ & $2000 \pm 50$ & $2800 \pm 50$ & $3200 \pm 50$ & $12000 \pm 100^{a}$ \\
$\left(V_{\mathrm{t}}-V_{\mathrm{o}}\right) / V_{0}$ & & & & \\
$\begin{array}{l}\text { over } 4000 \mathrm{~h} \\
\text { of operation }\end{array}$ & & & & \\
${ }^{a}$ Extrapolated value. & & & \\
\hline
\end{tabular}

Table 14 Improvement in operating voltage, efficiency, lifetime and voltage drift of EI-101, EI-111 and EI-111-2Me over LiF

\begin{tabular}{lcccc}
\hline Performance indicator & LiF & EI-101 & EI-111 & EI-111-2Me \\
\hline $\begin{array}{l}\text { Reduction in operating } \\
\text { voltage }\left(V_{\mathrm{op}}\right) \text { at } 1000 \mathrm{~cd} \mathrm{~m}^{-2}\end{array}$ & $0 \%$ & $16 \%$ & $31 \%$ & $22 \%$ \\
$\begin{array}{l}\text { Increase in current efficiency } \\
\left(\eta_{\mathrm{i}} / \mathrm{cd} \mathrm{A}^{-1}\right) \text { at } 1000 \mathrm{~cd} \mathrm{~m}^{-2}\end{array}$ & $0 \%$ & $54 \%$ & $31 \%$ & $69 \%$ \\
$\begin{array}{l}\text { Ratio of increase in lifetime } \\
\left(t_{1 / 2}\right) / \mathrm{h} \text { at an initial luminance }\end{array}$ & 1 & 1.4 & 1.6 & 6.00 \\
$\begin{array}{l}\text { of } 1000 \mathrm{~cd} \mathrm{~m}^{-2} \text { compared to LiF } \\
\begin{array}{l}\text { Percentage reduction in } \\
\text { normalised voltage drift } \\
\left(V_{\mathrm{t}}-V_{\mathrm{o}}\right) / V_{\mathrm{o}} \text { over } 4000 \mathrm{~h}\end{array} \\
\text { of operation compared to LiF }\end{array}$ & 0 & $33 \%$ & $36 \%$ & $41 \%$ \\
\hline
\end{tabular}

The fact that the drift voltage vs. time follows a double exponential equation indicates the voltage drift is also biphasic, just as in the case of luminance decay. The equation of this type is valuable as one could predict the maximum voltage drift over the device operation by setting $t=\infty$ (infinity). The maximum drift is calculated to be $0.595,0.426,0.423$ and $0.256 \mathrm{~V}$ for LiF, EI101, EI-111 and EI-111-2Me respectively. We note that devices could fail by a number of ways including catastrophic failure of an open circuit (layers becoming insulating due to the organic layers decomposing) with concomitant steep rise in voltage.

The lifetimes of the devices were monitored under constant current conditions from an initial luminance of 1029, 1046, 1052 and $1194 \mathrm{~cd} \mathrm{~m}^{-2}$ for LiF, EI-101, EI-111 and EI-111-2Me respectively. The half-life was estimated to be 2000, 2800, 3200 and 12000 hours for devices with LiF, EI-101, EI-111 and EI111-2Me respectively (Table 13).

It is clear that all the lithium complexes investigated here show improvements in operating voltage, current efficiency, power efficiency and lifetime compared to LiF (Table 14). However, EI111-2Me shows superior performance in all respects except for 


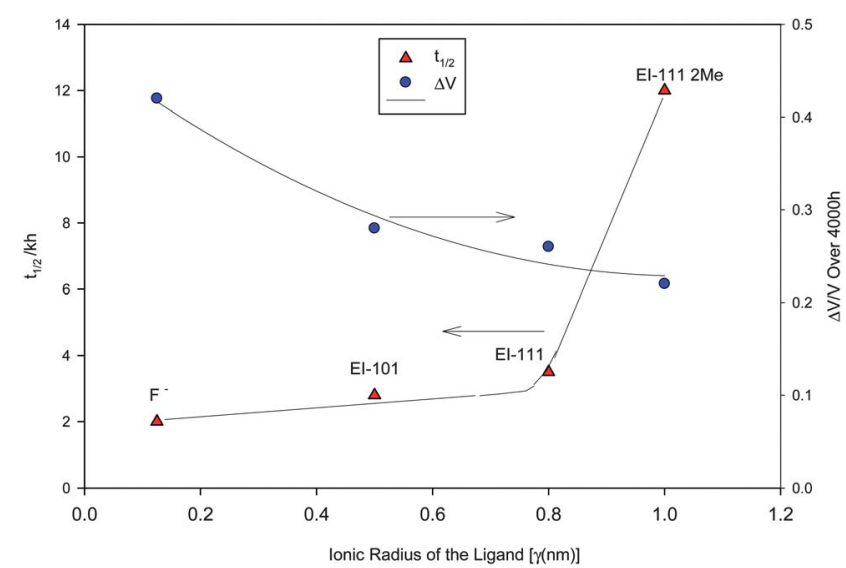

Fig. 19 Dependence of ionic radius of the ligands in $[\mathrm{LiL}]_{n}$ on half-life (kh) and drift voltage over $4000 \mathrm{~h}$ for ITO/ZnTPTP $(20 \mathrm{~nm}) / \alpha$-NPB $(50 \mathrm{~nm}) / \mathrm{Alq}_{3}:$ DPQA $(40: 0.1 \mathrm{~nm}) / \mathrm{Zrq}_{4}(20 \mathrm{~nm}) / \mathrm{EI}(1 \mathrm{~nm}) / \mathrm{Al}$ where EI: LiF, EI-101 (LiQ), EI-111, EI-111-2Me. Initial luminance: $1029 \mathrm{~cd} \mathrm{~m}^{-2}$ for LiF, $1046 \mathrm{~cd} \mathrm{~m}^{-2}$ for EI-101, $1052 \mathrm{~cd} \mathrm{~m}^{-2}$ for EI-111 and $1194 \mathrm{~cd} \mathrm{~m}^{-2}$ for EI-111-2Me.

the reduction in operating voltage compared to EI-111. Table 14 summarises the performance improvement provided by these lithium complexes compared to $\mathrm{LiF}$.

The remarkable increase (in excess of four-fold) in lifetime provided by EI-111-2Me in comparison to EI-101 (LiQ) indicates that there are other factors at play in addition to the presence of a low work function $\mathrm{Li}$ metal. These factors may include the nature of the ligand, the HOMO-LUMO levels of the electron injector, and the size of the anion.

Fig. 19 shows the dependence of the lifetime and drift voltage on the size of the anion. There seems to be a correlation between the size of the ligand of the lithium complex: the larger the size of the ligand, the longer the lifetime and the lower the drift voltage. This is consistent with the previous finding that diffusion of lithium $^{\mathbf{4 1 , 4 2}}$ into the etl and the host causes increased drift voltages and degradation of the devices, resulting in reduced lifetimes.

Low voltage drift $(\Delta V)$ and long lifetime are very important for stable operation of displays as otherwise an expensive compensation mechanism has to be built into the electronic drivers of the displays.

\section{Conclusion}

In this paper, we have compared the performance of fluorescent green OLEDs only with LiF, EI-101 (LiQ), EI-111 and EI-111$2 \mathrm{Me}$ as electron injectors. The lithium complexes of the Schiff bases show superior behaviour to LiF (similar behaviour has been observed for phosphorescent red and green and fluorescent blue devices: these results will be published elsewhere).

The current density vs. voltage characteristics of single-layer devices, $\mathrm{Li}-\mathrm{Al} / \mathrm{EI} / \mathrm{Li}-\mathrm{Al}$ and $\mathrm{Al} / \mathrm{EI} / \mathrm{Al}$ suggest that both sets of devices are operating as electron-only devices despite the work function of $\mathrm{Al}$ being $-4.2 \mathrm{eV}$ and that of $\mathrm{Li}-\mathrm{Al}$ being $-2.8 \mathrm{eV}$. This suggests that either the energetic aluminium atoms or the energetic lithium complexes generated under vacuum thermal evaporation are sufficient to lower the work function. This is an important finding as "inverted OLEDs" are easier to manufacture on an aluminium-deposited silicon backplane.

We conclude therefore that the primary reason for the reduction in operating voltage of the devices is due to the formation of free $\mathrm{Li}$ atoms which then transfer electrons to the electron transporter forming a complex of the type $\mathrm{Li}^{+}\left(\mathrm{Zrq}_{4}\right)^{-}$. The secondary reason is that the lithium complex itself forms a charge transfer complex at the interface, thereby providing a conducting pathway. The latter is supported by the increase in the conductivity of $\mathrm{Alq}_{3}$ on mixing with lithium complexes. We also found that the devices made with admixtures of $\mathrm{Alq}_{3}$ and Liq as electron transporters (ets) have a lower operating voltage than the virgin materials. In contrast, the devices fabricated with admixtures of $\mathrm{Zrq}_{4}$ and LiQ had a slightly higher operating voltage than neat $\mathrm{Zrq}_{4}$ as the et. The latter is further evidence that the production of free $\mathrm{Li}$ atoms at the interface is the primary cause of reduction of operating voltage.

Although it is known that the electron-withdrawing substituents usually depress the HOMO and LUMO levels, the lowering of the HOMO level on substituting a fluorine atom for a methyl group by up to $1.1 \mathrm{eV}$ is remarkable. This allows the tuning of HOMO-LUMO levels of the electron injectors with elegant simplicity.

\section{Acknowledgements}

We thank Dr T. Yuki and Mr Y. Nakajima of Pioneer, Japan, Dr C. Domto of Kyocera, Japan, Dr C. H. Lee and his colleagues at Samsung, Korea, Dr Y. Oh of LG Displays, Korea, Dr J. J. Lee of AUO, Taiwan and Mr Gong of Ritdisplay, Taiwan, for many stimulating discussions. We also thank Professors C. Jenks, M. Sarhadi, G. Rodgers and J. Silver (all of Brunel University) and Dr D. R. Rosseinsky (Exeter) for encouragement. We thank EPSRC for the award of a diffractometer.

\section{References}

1 (a) P. Kathirgamanathan, S. Surendrakumar, J. Antipan-Lara, S. Ravichandran, V. R. Reddy, S. Ganeshamurugan, M. Kumaraverl, V. Arkley, A. J. Blake and D. Bailey, J. Mater. Chem., 2011, 21, 1762-1771; (b) P. Kathirgamanathan, S. Surendrakumar, S. Ravichandran, R. R. Vanga, J. AntipanLara, S. Ganeshamurugan, M. Kumaraverl, G. Paramaswara and V. Arkley, Chem. Lett., 2010, 39, 1222-1224; (c) P. Kathirgamanathan, S. Surendrakumar, R. R. Vanga, S. Ravichandran, J. Antipan-Lara, S. Ganeshamurugan, M. Kumaraverl, G. Paramaswara and V. Arkley, Org. Electron., 2011, 12, 666-676.

2 P. Kathirgamanathan, V. Arkley, S. Surendrakumar, G. Paramaswara, J. Antipán-Lara, S. Ravichandran, S. Ganeshamurugan, M. Kumaraverl and Y. F. Chan, Asian Soc. for Information. Display, 2007, ISBN: 978-981-05-8143-5.

3 K. Ueno, A. Senoo and S. Mashmo, US Pat., 6436559B1, 20-08-2002.

4 S. H. Son, O. K. Kim, S. H. Yoon, K. K. Kim, Y. G. Lee and J. S. Bae, US Pat., 6720573B2, 13-04-2004.

5 K. P. Klubeck and D. Y. Kondakov, US Pat., 2007/0122657, 31-052007.

6 P. Kathirgamanathan, V. Kandappu, S. Hara, K. Chandrakumar, S. L. Marianesan, S. Selvaranjan, S. Surendrakumar and M. J. Toohey, Mater. Lett., 1999, 40, 285.

7 S. Reinnke, F. Lindner, G. Schwartz, N. Seidler, K. Walzer, B. Lussem and K. Leo, Nature, 2009, 459, 234.

8 H. Sasabe, T. Chiba, S. J. Su, Y.-J. Pu, K. Naayama and J. Kido, Chem. Commun., 2008, 5821.

9 J. J. Brown, IMID, OLED Workshop, Korea, 2007. 
10 J. Endo, T. Matsumoto and J. Kido, Jpn. J. Appl. Phys., 2002, 41, L358.

11 I. D. Parker, J. Appl. Phys., 1994, 75, 1656.

12 A. J. Heeger, I. D. Parker and Y. Yang, Synth. Met., 1994, 67, 23.

13 R. Partridge, US Pat., 1976/3995299, 1976.

14 C. W. Tang, US Pat., 1982/4356429, 1982.

15 C. W. Tang and S. A. Van Slyke, Appl. Phys. Lett., 1987, 51, 913.

16 J. H. Burroughes, D. D. C. Bradley, A. R. Brown, R. N. Marks, K. Mackay, R. H. Friend, P. L. Burn and A. B. Holmes, Nature, 1990, 347, 539.

17 J. Kido, K. Nagai and Y. Okamoto, IEEE Trans. Electron Devices, 1997, 44, 1245 .

18 T. Wakimoto, Y. Fukuda, K. Nagayama, A. Yokoi, H. Nakada and M. Tsuchida, IEEE Trans. Electron Devices, 1997, 44, 1245.

19 L. S. Hung, C. W. Tang and M. G. Mason, Appl. Phys. Lett., 1997, 70, 152.

20 C. I. Wu, G. R. Lee and T. W. Pi, Appl. Phys. Lett., 2005, 87, 212108.

21 K. W. Wong, Y. M. Wang, S. T. Lee and R. W. M. Kwok, Diamond Relat. Mater., 1999, 8, 1885.

22 P. Kathirgamanathan, Eur Pat., 1458834, 2000.

23 W. J. Begley and M. Rajeswaran, Acta Crystallogr., Sect. E: Struct. Rep. Online, 2006, 62, m200.

24 M. Rajeswaran, W. J. Begley, L. O. Olson and S. Huo, Polyhedron, 2007, 26, 3653

25 E. Bohm, C. Pflumm, F. Voges, M. Flammich, H. Heil, A. Busing, A. Parham, R. Fortte and T. Mujica, IDW Proceedings, 2009, p. 431.

26 Y. Li, D. Zhang, L. Duan, R. Zhang, L. Wang, J. Qiao and Y. Qiu, Jpn. J. Appl. Phys., 2006, 45, L1253.

27 P. Kathirgamanathan, V. Arkley, S. Surendrakumar, Y. F. Chan, S. Ravichandran, S. Ganeshamurugan, M. Kumaraverl, J. AntipanLara, G. Paramaswara and V. R. Reddy, Dig. Tech. Pap. - Soc. Inf. Disp. Int. Symp., 2010, 32.2, 465.

28 Y. J. Pu, M. Miyamoto, K. Nakayama, T. Oyama, Y. Masaaki and J. Kido, Org. Electron., 2009, 10, 228.

29 S. G. Schulman and M. S. Rietta, Anal. Chem., 1971, 60, 1762.

$30 \mathrm{P}$. Kathirgamanathan and G. Paramaswara, unpublished work, carried out by Huntingdon Life Sciences under contract.

31 B. N. Ames, J. MCCann and E. Yamasaki, Mutat. Res., 1975, 31, 347.
32 D. M. Maron and B. N. Ames, Mutat. Res., 1983, 113, 173-215.

33 X. Sun, D. Y. Zhou, L. Qiu, L. S. Lao and F. Yan, J. Phys. Chem. C, 2011, 115, 2433

34 Y. Kim, Nanotechnology, 2008, 19, 355207.

35 P. Kathirgamanathan and D. R. Rosseinsky, J. Chem. Soc., Chem. Commun., 1980, 839.

36 (a) P. Kathirgamanathan, US Pat., 2005/0106412 A1, 2005; (b) P. Kathirgamanathan, S. Surendrakumar and Y. F. Chan, US Pat., 2011/0108819A1, 2011.

37 M. Cole and W. Brutting, Physics of Organic Semiconductors, WileyVCH Verlag GmBH, 2005, pp. 95-128, ISBN-13: 978-3-52740550-3.

38 A. J. Heeger, I. D. Parker and Y. Yang, Synth. Met., 1994, 67, 23.

39 J. Antipán-Lara and P. Kathirgamanathan, IEE Proc.: Optoelectron., 2000, 147, 369.

40 M. A. Lampert and P. Mark, Current Injection in Solids, Academic Press, New York, 1970, ISBN: 75-117115.

41 C. K. Tzen, W. J. Shen, Y. L. Kao and S. J. Tang, IDW/AD'05, Sunport Takamatsu, Japan, Proceedings of the 12th International Display Workshops in Conjunction with Asia Display, 2005, p. 621.

42 S. Madhusoodhanan, E. Polikarpov, S. Garon and M. E. Thompson, Proceedings of the International Symposium Super Functionality Organic Devices, IPAP Conf. Series 6, pp. 110-113, 2009.

43 P. Kathirgamanathan and Y. F. Chan, PCT WO 2008/081178, 2008.

44 (a) J. Bredas and A. Heeger, Chem. Phys. Lett., 1994, 217, 507; (b) D. R. Baigent, N. C. Greenham, J. Grunner, R. N. Marks, R. H. Friend, S. C. Moratti and A. R. Holmes, Synth. Met., 1994, 67(1-3), 3.

45 P. Kathirgamanathan, M. A. Mazid and D. R. Rosseinsky, J. Chem. Soc., Perkin Trans. 2, 1982, 593.

46 P. Kathirgamanathan, High Value Polymers, Special Publication No: 87, Royal Society of Chemistry, 1991, pp. 174-205, ISBN 0-85186867-3.

47 L. B. Valdes, Proc. IRE, 1954, 42, 420.

48 L. J. Van der Pauw, Philips Res. Rep., 1958, 13, 1.

49 L. J. van der Pauw, Philips Tech. Rev., 1959, 20, 220.

50 L. J. Van der Pauw, Philips Res. Rep., 1961, 16, 187.

51 P. Kathirgamanathan, PhD thesis, Exeter, 1980. 